\title{
Global spatial risk assessment of sharks under the footprint of fisheries
}

Nuno Queiroz ${ }^{1,2}$, Nicolas E. Humphries ${ }^{2}$, Ana Couto ${ }^{1}$, Marisa Vedor ${ }^{1,3}$, Ivo da Costa $^{1}$, Ana M.M. Sequeira ${ }^{4,5}$, Gonzalo Mucientes ${ }^{1}$, António M. Santos ${ }^{1,3}$, Francisco J. Abascal ${ }^{6}$, Debra L. Abercrombie $^{7}$, Katya Abrantes ${ }^{8}$, David Acuña-Marrero ${ }^{9}$, André S. Afonso ${ }^{10,11}$, Pedro Afonso $^{12,13,14}$, Darrell Anders ${ }^{15}$, Gonzalo Araujo ${ }^{16}$, Randall Arauz ${ }^{17,18,19}$, Pascal Bach ${ }^{20}$, Adam Barnett $^{8}$, Diego Bernal ${ }^{21}$, Michael L. Berumen ${ }^{22}$, Sandra Bessudo Lion ${ }^{19,23}$, Natalia P. A. Bezerra $^{10}$, Antonin V. Blaison ${ }^{20}$, Barbara A. Block ${ }^{24}$, Mark E. Bond ${ }^{25}$, Ramon Bonfil ${ }^{26}$, Russell W. Bradford ${ }^{27}$, Camrin D. Braun ${ }^{28}$, Edward J. Brooks ${ }^{29}$, Annabelle Brooks ${ }^{29,30}$, Judith Brown $^{31}$, Barry D. Bruce ${ }^{27}$, Michael E. Byrne ${ }^{32,33}$, Steven E. Campana ${ }^{34}$, Aaron B. Carlisle ${ }^{35}$, Demian D. Chapman ${ }^{25}$, Taylor K. Chapple ${ }^{24}$, John Chisholm ${ }^{36}$, Christopher R. Clarke ${ }^{37}$, Eric G. Clua ${ }^{38}$, Jesse E. M. Cochran ${ }^{22}$, Estelle C. Crochelet ${ }^{39,40}$, Laurent Dagorn ${ }^{20}$, Ryan Daly ${ }^{41,42}$, Daniel Devia Cortés ${ }^{43}$, Thomas K. Doyle ${ }^{44,45}$, Michael Drew ${ }^{46}$, Clinton A. J. Duffy ${ }^{47}$, Thor Erikson $^{48}$, Eduardo Espinoza ${ }^{19,49}$, Luciana C. Ferreira ${ }^{50}$, Francesco Ferretti2 ${ }^{24}$, John D. Filmalter $^{20,42}$, G. Chris Fischer ${ }^{51}$, Richard Fitzpatrick ${ }^{8}$, Jorge Fontes ${ }^{12,13,14}$, Fabien Forget ${ }^{20}$, Mark Fowler ${ }^{52}$, Malcolm P. Francis ${ }^{53}$, Austin J. Gallagher ${ }^{54,55}$, Enrico Gennari ${ }^{42,56,57}$, Simon D. Goldsworthy ${ }^{58}$, Matthew J. Gollock ${ }^{59}$, Jonathan R. Green ${ }^{60}$, Johan A. Gustafson ${ }^{61}$, Tristan L. Guttridge ${ }^{62}$, Hector M. Guzman ${ }^{63}$, Neil Hammerschlag ${ }^{55,64}$, Luke Harman ${ }^{44}$, Fábio H. V. Hazin $^{10}$, Matthew Heard ${ }^{46}$, Alex R. Hearn ${ }^{19,65,66}$, John C. Holdsworth ${ }^{67}$, Bonnie J. Holmes ${ }^{68}$, Lucy A. Howey ${ }^{69}$, Mauricio Hoyos ${ }^{19,70}$, Robert E. Hueter ${ }^{71}$, Nigel E. Hussey ${ }^{72}$, Charlie Huveneers $^{46}$, Dylan T. Irion ${ }^{73}$, David M.P. Jacoby ${ }^{74}$, Oliver J. D. Jewell ${ }^{75,76}$, Ryan Johnson ${ }^{77}$, Lance K. B. Jordan ${ }^{69}$, Salvador J. Jorgensen ${ }^{78}$, Warren Joyce ${ }^{52}$, Clare A. Keating Daly ${ }^{41}$, James T. Ketchum ${ }^{19,70}$, A. Peter Klimley ${ }^{19,79}$, Alison A. Kock ${ }^{42,80,81,82}$, Pieter Koen ${ }^{83}$, Felipe Ladino $^{23}$, Fernanda O. Lana ${ }^{84}$, James S.E. Lea ${ }^{37,85}$, Fiona Llewellyn ${ }^{59}$, Warrick S. Lyon ${ }^{53}$, Anna MacDonnell ${ }^{52}$, Bruno C. L. Macena ${ }^{10,13}$, Heather Marshall ${ }^{21,86}$, Jaime D. McAllister ${ }^{87}$, 
Rory McAuley ${ }^{88,89}$, Michael A. Meÿer ${ }^{15}$, John J. Morris ${ }^{71}$, Emily R. Nelson ${ }^{55}$, Yannis P. Papastamatiou $^{25}$, Toby A. Patterson ${ }^{27}$, Cesar Peñaherrera-Palma ${ }^{19,90}$, Julian G. Pepperell ${ }^{91}$, Simon J. Pierce ${ }^{92}$, Francois Poisson ${ }^{20}$, Lina Maria Quintero ${ }^{23}$, Andrew J. Richardson ${ }^{93}$, Paul J. Rogers $^{58}$, Christoph A. Rohner ${ }^{92}$, David R.L. Rowat ${ }^{94}$, Melita Samoilys ${ }^{95}$, Jayson M. Semmens $^{87}$, Marcus Sheaves ${ }^{8}$, George Shillinger ${ }^{19,24,96}$, Mahmood Shivji ${ }^{31}$, Sarika Singh ${ }^{15}$, Gregory B. Skomal ${ }^{36}$, Malcolm J. Smale ${ }^{97}$, Laurenne B. Snyders ${ }^{15}$, German Soler ${ }^{19,23,87}$, Marc Soria $^{20}$, Kilian M. Stehfest ${ }^{87}$, John D. Stevens ${ }^{26}$, Simon R. Thorrold ${ }^{98}$, Mariana T. Tolotti ${ }^{20}$, Alison Towner ${ }^{57,76}$, Paulo Travassos ${ }^{10}$, John P. Tyminski ${ }^{71}$, Frederic Vandeperre ${ }^{12,13,14}$, Jeremy J. Vaudo ${ }^{31}$, Yuuki Y. Watanabe ${ }^{99,100}$, Sam B. Weber ${ }^{101}$, Bradley M. Wetherbee ${ }^{32,102}$, Timothy D. White ${ }^{24}$, Sean Williams ${ }^{29}$, Patricia M. Zárate ${ }^{19,103}$, Robert Harcourt ${ }^{104}$, Graeme C. Hays $^{105}$, Mark G. Meekan ${ }^{50}$, Michele Thums ${ }^{50}$, Xabier Irigoien ${ }^{106,107}$, Victor M. Eguiluz ${ }^{108}$, Carlos M. Duarte ${ }^{22}$, Lara L. Sousa ${ }^{2,109}$, Samantha J. Simpson ${ }^{2,110}$, Emily J. Southall ${ }^{2}$ \& David W. Sims $2,110,111 *$

1 Centro de Investigação em Biodiversidade e Recursos Genéticos/Research Network in Biodiversity and Evolutionary Biology, Campus Agrário de Vairão, Universidade do Porto, 4485-668 Vairão, Portugal

2 Marine Biological Association of the United Kingdom, The Laboratory, Citadel Hill, Plymouth PL1 2PB, UK

3 Dep. Biologia, Faculdade de Ciências da Universidade do Porto, 4169-007 Porto, Portugal

4 UWA Oceans Institute, Indian Ocean Marine Research Centre, University of Western Australia, Crawley, WA 6009, Australia 
Nature 572, 461-466 (2019) doi: 10.1038/s41586-019-1444-4 (Accepted version)

5 School of Biological Sciences, University of Western Australia, Crawley, WA 6009, Australia

6 Spanish Institute of Oceanography, Vía Espaldón, Dársena Pesquera PCL8, 38180 Santa Cruz de Tenerife, Spain

7 Abercrombie and Fish, 14 Dayton Avenue, Port Jefferson Station, NY 11776, USA

8 Marine Biology and Aquaculture Unit, College of Science and Engineering, James Cook University, Cairns, QLD, Australia

9 Institute of Natural and Mathematical Sciences, Massey University, New Zealand

10 UFRPE (Universidade Federal Rural de Pernambuco), Departamento de Pesca e Aquicultura, Rua Dom Manoel de Medeiros, s/n, 52171-900, Recife- PE, Brazil

11 MARE, Marine and Environmental Sciences Centre, Instituto Politécnico de Leiria, Av. do Porto de Pesca 30, 2520-208 Peniche, Portugal.

12 MARE, Laboratório Marítimo da Guia, Faculdade de Ciências da Universidade de Lisboa, Av. Nossa Senhora do Cabo, 939, 2750-374 Cascais, Portugal

13 IMAR - Institute of Marine Research, Departamento de Oceanografia e Pescas, Universidade dos Açores, Horta, Portugal

14 Okeanos - Departamento de Oceanografia e Pescas, Universidade dos Açores, Horta, Portugal

15 Department of Environmental Affairs, Oceans and Coasts Research, P.O. Box 52126, Victoria \& Alfred Waterfront, Cape Town 8001, South Africa 
Nature 572, 461-466 (2019) doi: 10.1038/s41586-019-1444-4 (Accepted version)

16 Large Marine Vertebrates Research Institute Philippines, Cagulada Compound, Tejero, Jagna, 6308, Bohol, Philippines

17 Fins Attached Marine Research and Conservation, 19675 Still Glen Way, Colorado Springs, CO 80908, USA

18 Programa Restauración de Tortugas Marinas PRETOMA, 1203-1100, Tibás, San José, Costa Rica

19 MigraMar, 9255 Sir Francis Drake Boulevard, Olema, CA 94950, USA

20 Institut de Recherche pour le Développement, UMR MARBEC (IRD, Ifremer, Univ. Montpellier, CNRS), Sète, France

21 University of Massachusetts Dartmouth, Biology Department, Dartmouth, MA, USA

22 Red Sea Research Center, Division of Biological and Environmental Science and Engineering, King Abdullah University of Science and Technology, Thuwal, 23955, Kingdom of Saudi Arabia

23 Fundación Malpelo y Otros Ecosistemas Marinos, Carrera 11 \# 87 - 51 Local 4 Piso 2, Bogota, Columbia

24 Hopkins Marine Station of Stanford University, 120 Oceanview Blvd., Pacific Grove, CA 93950, USA

25 Department of Biological Sciences, Florida International University, 3000 NE 151st Street, North Miami, FL 33181 USA

26 Océanos Vivientes, Mexico City, Mexico

27 CSIRO Oceans and Atmosphere, GPO Box 1538, Hobart, TAS 7000, Australia 
Nature 572, 461-466 (2019) doi: 10.1038/s41586-019-1444-4 (Accepted version)

28 Massachusetts Institute of Technology-Woods Hole Oceanographic Institution Joint Program in Oceanography/Applied Ocean Science and Engineering, Cambridge, MA USA

29 Shark Research and Conservation Program, Cape Eleuthera Institute, Eleuthera, The Bahamas

30 University of Exeter, Prince of Wales Road, Exeter, EX4 4PS, UK

31 South Atlantic Environmental Research Institute, Stanley Cottage, FIQQ 1ZZ, Falkland Islands

32 Department of Biological Sciences, The Guy Harvey Research Institute, Nova Southeastern University, Dania Beach, FL, USA

33 School of Natural Resources, University of Missouri, Columbia, MO, USA

34 Life and Environmental Sciences, University of Iceland, Reykjavik, Iceland

35 School of Marine Science and Policy, University of Delaware, 700 Pilottown Rd., Lewes, DE 19958, USA

36 Massachusetts Division of Marine Fisheries, New Bedford, MA USA

37 Marine Research Facility, Jeddah, Saudi Arabia

38 PSL, Labex CORAIL, CRIOBE USR3278 EPHE-CNRS-UPVD, PoBox 1013, 98729 Papetoai, French Polynesia

39 Agence de Recherche pour la Biodiversité à la Réunion (ARBRE), Réunion, France

40 Institut de Recherche pour le Développement, UMR 228 ESPACE-DEV, Réunion, France 
Nature 572, 461-466 (2019) doi: 10.1038/s41586-019-1444-4 (Accepted version)

41 Save Our Seas Foundation - D'Arros Research Centre (SOSF-DRC), Rue Philippe Plantamour 20, CH-1201 Geneva, Switzerland

42 South African Institute for Aquatic Biodiversity (SAIAB), Private Bag 1015, Grahamstown 6140, South Africa

43 Department of Fisheries Evaluation, Fisheries Research Division, Instituto de Fomento Pesquero (IFOP), Blanco 839, Valparaíso 2361827, Chile

44 School of Biological, Earth and Environmental Sciences, University College Cork, Ireland

45 MaREI Centre, Environmental Research Institute, University College Cork, Ireland

46 College of Science and Engineering, Flinders University, GPO Box 2100, Adelaide, SA, Australia

47 Department of Conservation, Private Bag 68908, Auckland, New Zealand

48 South African Institute for Aquatic Biodiversity, Geological Sciences, UKZN, Durban, 4001, South Africa

49 Direccion Parque Nacional Galapagos, Puerto Ayora, Galapagos, Ecuador

50 Australian Institute of Marine Science, Indian Ocean Marine Research Centre (UWA), 35 Stirling Hwy, Crawley 6009 WA, Australia

51 OCEARCH, Park City, Utah 84060, USA

52 Bedford Institute of Oceanography, Dartmouth, NS Canada

53 National Institute of Water and Atmospheric Research, Private Bag 14901, Wellington, New Zealand 
Nature 572, 461-466 (2019) doi: 10.1038/s41586-019-1444-4 (Accepted version)

54 Beneath the Waves, Herndon, VA, USA

55 Rosenstiel School of Marine and Atmospheric Science, University of Miami, 4600 Rickenbacker Causeway, Miami, FL 33149, USA

56 Oceans Research, PO box 1767, Mossel Bay 6500, South Africa

57 Department of Ichthyology and Fisheries Science, Rhodes University, Grahamstown, South Africa

58 SARDI Aquatic Sciences, Henley Beach, Adelaide, South Australia, 5022, Australia

59 Zoological Society of London, Regent's Park, London, NW1 4RY, UK

60 Galapagos Whale Shark Project, Galapagos Islands, Ecuador

61 Griffith Centre for Coastal Management, Griffith University School of Engineering, Griffith University, Gold Coast, Queensland, 4222, Australia

62 Bimini Biological Field Station, 15 Elizabeth Drive, South Bimini, Bahamas

63 Smithsonian Tropical Research Institute, PO Box 0843-03092, Panama, Republic of Panama

64 Leonard and Jayne Abess Center for Ecosystem Science and Policy, University of Miami, 1365 Memorial Drive, \#230, Coral Gables, FL 33146, USA

65 Galapagos Science Center, San Cristobal, Galapagos, Ecuador

66 Universidad San Francisco de Quito, Diego de Robles s/n y Pampite, Cumbaya, Quito, Ecuador

67 Blue Water Marine Research, PO Box 402081, Tutukaka, New Zealand 
Nature 572, 461-466 (2019) doi: 10.1038/s41586-019-1444-4 (Accepted version)

68 University of Queensland, St Lucia, Brisbane, Queensland 4001, Australia

69 Microwave Telemetry, Inc., Columbia, MD, USA

70 Pelagios-Kakunja, Cuauhtémoc 155, Pueblo Nuevo, 23060 La Paz, Mexico

71 Mote Marine Laboratory, Center for Shark Research, Sarasota, FL 34236, USA

72 University of Windsor, Biological Sciences, 401 Sunset Avenue, Windsor, Ontario, N9B 3P4, Canada

73 Cape Research and Diver Development, Simon's Town, South Africa

74 Institute of Zoology, Zoological Society of London, Regent's Park, London, NW1 4RY, UK

75 Centre for Sustainable Aquatic Ecosystems, Harry Butler Institute, Murdoch University, Western Australia

76 Dyer Island Conservation Trust, Kleinbaai, Western Cape, South Africa

77 Blue Wilderness Research Unit, 11 Escombe Cresent, Freeland Park, Scottburgh, 4180, South Africa

78 Monterey Bay Aquarium, 886 Cannery Row, Monterey, CA 93940, USA

79 University of California Davis, Davis, CA 95616, USA

80 Cape Research Centre, South African National Parks, South Africa

81 Shark Spotters, P. O. Box 22581, Fish Hoek, 7974, South Africa

82 Institute for Communities and Wildlife in Africa, Department of Biological Sciences, University of Cape Town, Private Bag X3, Rondebosch 7701, South Africa 
Nature 572, 461-466 (2019) doi: 10.1038/s41586-019-1444-4 (Accepted version)

83 Western Cape Department of Agriculture, Veterinary Services, Private Bag X1, Elsenburg, 7607 South Africa

84 UFF (Universidade Federal Fluminense), Departamento de Biologia Marinha, Rua Alexandre Moura, 24210-200, Niterói- RJ, Brazil

85 Department of Zoology, University of Cambridge, Downing Street, Cambridge CB2 3EJ, UK

86 Atlantic White Shark Conservancy, Chatham, MA, USA

87 Fisheries and Aquaculture Centre, Institute for Marine and Antarctic Studies, University of Tasmania, Private Bag 49, Hobart, TAS 7001, Australia

88 Department of Fisheries, Government of Western Australia, 39 Northside Dr, Hillarys WA 6025, Australia

89 Minderoo Foundation, Flourishing Oceans Initiative, P.O. Box 3155, Broadway, Nedlands, WA 6009, Australia

90 Pontificia Universidad Católica del Ecuador Sede Manabi, Portoviejo 130103, Ecuador

91 Pepperell Research \& Consulting Pty LTD, PO Box 1475, Noosaville BC, Queensland 4565, Australia

92 Marine Megafauna Foundation, 11260 Donner Pass Road, Truckee, CA 96161, USA

93 Conservation and Fisheries Department, Ascension Island Government, Ascension Island, South Atlantic ASCN 1ZZ

94 Marine Conservation Society Seychelles, PO Box 384, Victoria, Mahe, Seychelles

95 CORDIO, East Africa, PO Box 10135, Mombasa, 80101, Kenya 
Nature 572, 461-466 (2019) doi: 10.1038/s41586-019-1444-4 (Accepted version)

96 Upwell, Heritage Harbor Complex, 99 Pacific Street, Suite 375-E, Monterey, CA 93940, USA

97 Department of Zoology and Institute for Coastal and Marine Research, Nelson Mandela University, South Africa

98 Biology Department, Woods Hole Oceanographic Institution, Woods Hole, MA, USA

99 National Institute of Polar Research, Tachikawa, Tokyo 190-8518, Japan

100 Department of Polar Science, SOKENDAI (The Graduate University for Advanced Studies), Tachikawa, Tokyo 190-8518, Japan

101 Centre for Ecology and Conservation, University of Exeter, Penryn Campus, Cornwall TR10 9FE, UK

102 Department of Biological Sciences, University of Rhode Island, Kingston RI, USA

103 Department of Oceanography and Environment, Fisheries Research Division, Instituto de Fomento Pesquero (IFOP), Blanco 839, Valparaíso 2361827, Chile

104 Department of Biological Sciences, Macquarie University, Sydney, NSW2109, Australia 105 School of Life and Environmental Sciences, Deakin University, Geelong, Victoria, Australia

106 AZTI - Marine Research, Herrera Kaia, Portualdea z/g - 20110 Pasaia (Gipuzkoa), Spain

107 IKERBASQUE, Basque Foundation for Science, Bilbao, Spain

108 Instituto de Fisica Interdisciplinar y Sistemas Complejos, Consejo Superior de Investigaciones Cientificas - University of the Balearic Islands, E-07122 Palma de Mallorca, Spain 
Nature 572, 461-466 (2019) doi: 10.1038/s41586-019-1444-4 (Accepted version)

109 Wildlife Conservation Research Unit, Department of Zoology, University of Oxford, Abingdon Road, Tubney OX13 5QL, UK

110 Ocean and Earth Science, University of Southampton, National Oceanography Centre Southampton, Waterfront Campus, European Way, Southampton SO14 3ZH, UK

111 Centre for Biological Sciences, University of Southampton, Building 85, Highfield Campus, Southampton SO17 1BJ, UK

*e-mail: dws@mba.ac.uk 
Effective ocean management and conservation of highly migratory species depends on resolving overlap between animal movements and distributions, and fishing effort. However, this information is lacking at a global scale. Here we show, using a big-data approach that combines satellite-tracked movements of pelagic sharks and global fishing fleets, that $24 \%$ of the mean monthly space used by sharks falls under the footprint of pelagic longline fisheries. Space-use hotspots of commercially valuable sharks and of internationally protected species had the highest overlap with longlines (up to $76 \%$ and 64\%, respectively), and were also associated with significant increases in fishing effort. We conclude that pelagic sharks have limited spatial refuge from current levels of fishing effort in marine areas beyond national jurisdictions (the high seas). Our results demonstrate an urgent need for conservation and management measures at high-seas hotspots of shark space use, and highlight the potential of simultaneous satellite surveillance of megafauna and fishers as a tool for near-real-time, dynamic management.

Industrialised fishing is a major source of mortality for large marine animals (marine megafauna $)^{1-6}$. Humans have hunted megafauna in the open ocean for at least 42,000 years ${ }^{7}$, but international fishing fleets targeting large, epipelagic fishes did not spread into the high seas (areas beyond national jurisdiction) until the $1950 \mathrm{~s}^{8}$. Prior to this, the high seas constituted a spatial refuge largely free from exploitation as fishing pressure was concentrated on continental shelves ${ }^{3,8}$. Pelagic sharks are among the widest ranging vertebrates, with some species exhibiting annual ocean-basin-scale migrations ${ }^{9}$, long term trans-ocean movements ${ }^{10}$, and/or fine-scale site fidelity to preferred shelf and open ocean areas ${ }^{5,9,11}$. These behaviours could cause extensive spatial overlap with different fisheries from coastal areas to the deep ocean. On average, large pelagic sharks account for $52 \%$ of all identified shark catch worldwide in target fisheries or as bycatch ${ }^{12}$. Regional declines in abundance of pelagic sharks have been reported $^{13,14}$, but it is unclear whether exposure to high fishing effort extends across ocean- 
wide population ranges and overlaps areas in the high seas where sharks are most abundant ${ }^{5,13}$. Conservation of pelagic sharks - which currently have limited high seas management ${ }^{12,15,16}$ would benefit greatly from a clearer understanding of the spatial relationships between sharks' habitats and active fishing zones. However, obtaining unbiased estimates of shark and fisher distributions is complicated by the fact that most data on pelagic sharks come from catch records and other fishery-dependent sources ${ }^{4,15,16}$.

Here, we provide the first global estimate of the extent of space use overlap of sharks with industrial fisheries. This is based on the analysis of the movements of pelagic sharks tagged with satellite transmitters in the Atlantic, Indian and Pacific oceans, together with fishing vessel movements monitored globally by the Automatic Identification System (AIS), developed as a vessel safety and anti-collision system (see Methods). Our study focused on 23 species of large pelagic sharks that occupy oceanic and/or neritic habitats spanning broad distributions from cold-temperate to tropical waters (Supplementary Table 1). All these species face some level of fishing pressure in coastal, shelf and/or high-seas fisheries, with the International Union for the Conservation of Nature (IUCN) Red List assessing almost two thirds as being Endangered $(26 \%)$ or Vulnerable (39\%), and a further quarter as Near Threatened (26\%) (Supplementary Table 2). Regional fisheries management organizations (RFMOs) are tasked with the management of sharks in high seas areas, yet little or no management is in place for most species $^{3,5,12-18}$.

\section{Movement patterns of sharks and fishing vessels}

Eleven of the largest shark species/taxa groups accounted for $96 \%$ of the 1,804 satellite tags deployed (blue Prionace glauca; shortfin mako Isurus oxyrinchus; tiger Galeocerdo cuvier; salmon Lamna ditropis; whale Rhincodon typus; white Carcharodon carcharias; oceanic whitetip Carcharhinus longimanus; porbeagle Lamna nasus; silky Carcharhinus falciformis; 
bull Carcharhinus leucas; and hammerhead Sphyrna spp. sharks) (Supplementary Tables 3-5). Movement patterns indicated that multiple species aggregated within the same major oceanographic features (Fig. 1), such as the Gulf Stream (blue, shortfin mako, tiger, white and porbeagle sharks), the California Current (blue, shortfin mako, white and salmon sharks), and in the East Australian Current (blue, shortfin mako, tiger, white and porbeagle sharks), (Extended Data Fig. 1; Supplementary Results and Discussion 2.1). The global relative density map (Fig. 2a) reveals distribution patterns of pelagic sharks and locations of space use hotspots (defined here as those areas with $\geq 75^{\text {th }}$ percentile of weighted daily location density; Methods). Major hotspots of tracked pelagic sharks in the Atlantic Ocean were in the Gulf Stream and its western approaches, Caribbean Sea, Gulf of Mexico and around oceanic islands such as the Azores (Fig. 2a; Supplementary Table 6). In the Indian Ocean, hotspots were evident in the Agulhas Current, Mozambique Channel, the South Australian Basin and northwest Australia, while Pacific hotspots were in the California Current, Galapagos Islands, and around New Zealand. Although tagging sites occurred as expected in some shark space use hotspots - as tagging rates are inherently higher in hotspots - we also identified hotspots where no tagging sites occurred: in the North Atlantic (outer Gulf Stream, Charlie Gibbs Fracture Zone, western European shelf edge and Bay of Biscay); Indian Ocean (southern Madagascar, Crozet and Amsterdam Islands, South Australian Basin); and the Pacific (Alaska Current, outer California Current, white shark 'Café' area ${ }^{11}$, North Equatorial Current, Clipperton Island, Kermadec Islands) (Extended Data Fig. 1). There was consistency between our fine-scale shark hotspots and coarse scale hotspots estimated from fishery-dependent catch data (Supplementary Results and Discussion 2.1).

To determine the extent to which shark space use hotspots fall under the footprint of global industrialised fisheries we mapped the movements of fishing vessels carrying AIS transmitters, estimated to be fitted on $50-75 \%$ of active vessels $>24 \mathrm{~m}$ length ${ }^{19-22}$. Firstly we mapped the 
mean annual and mean monthly fishing effort (days) of AIS-equipped fishing vessels using various gear types ${ }^{19}$ during 2012-2016 (Extended Data Fig. 2; Methods) and then mapped the estimated global fishing effort of drifting pelagic longline and purse seine vessels separately as these two gears catch the majority of pelagic sharks ${ }^{12,15}$ (Fig. 2b; Extended Data Fig. 2). The global distribution map of longline fishing effort identifies several large-scale, high-use areas such as the North Atlantic, southwest Indian Ocean, and the central equatorial and northwest Pacific regions (Fig. 2b; Extended Data Figs. 1, 2). There were also areas where industrial longline activity appeared sparse, for example the central and southwest North Atlantic, northeast Pacific, and northern Indian oceans. We focused our detailed analysis of shark overlap with that of longline fishing effort, as this gear catches most pelagic sharks globally ${ }^{15}$ and since most other AIS fishing vessel gear types represented in the dataset do not target or generate abundant bycatch of pelagic sharks ${ }^{19}$ (Supplementary Results and Discussion 2.2). The number of Atlantic AIS longline fishing effort days was positively correlated with the number of observed baited longline hooks deployed in the Atlantic (observed hooks, Spearman's $r=0.182, p=0.008 ; n=241$; see Methods), confirming AIS longline fishing effort days were indicative of actual fishing effort ${ }^{19}$.

\section{Spatial overlap of sharks and fishing effort}

To explore the spatial heterogeneities of sharks and vessels, we used generalised additive models to determine how shark relative density of location estimates and longline fishing effort were affected by environmental covariates (see Methods; Supplementary Table 7). Distributions of pelagic shark density and fishing effort of pelagic longline vessels were best explained by the same drivers, with both demonstrating strong relationships with habitat types characterised by surface and subsurface temperature gradients (fronts ${ }^{23}$; thermoclines) and/or high primary productivity (Supplementary Table 8, Extended Data Fig. 3; Supplementary 
Results and Discussion 2.3). The similar environmental drivers identified predict high spatial overlap because sharks are known to aggregate in biologically productive features like fronts to enhance foraging opportunities ${ }^{5,6,23}$, a behaviour that fishers exploit to increase their chances of making higher catches of commercially valuable epipelagic fishes, including sharks 5 .

We calculated the spatial overlap of tracked sharks with longline fishing effort for a mean month within the datasets (Methods). Overlap was defined as shark and fishing effort spatial co-occurrence within a $1 \times 1^{\circ}$ grid cell in an average month (Methods) (for grid-cell size analysis see Supplementary Table 9, Extended Data Fig. 4, Supplementary Results and Discussion 2.4). Overlap between tracked sharks' space use was dominated by pelagic longline gear (Fig. 2; compare longline distribution in Fig. 2b with all AIS fishing vessels in Extended Data Fig. 2a). Globally, the distribution of longline fishing activity in the dataset overlapped $24 \%$ of the mean monthly space use of tracked sharks at the $1 \times 1^{\circ}$ scale (mean monthly overlap $=23.7 \% \pm 32.7$ S.D.; median $=4.5 \%, n=1,681$ tracks). This estimate is unlikely to be biased by a majority of our tags being deployed in the northwest Atlantic or northeast Pacific oceans because there was relatively low AIS-monitored longline fishing effort in both regions (Figs. 1a, 2a-c). Across four regions where the majority of sharks were tracked, mean monthly spatial overlap of the 11 most frequently tracked species/taxa groups with longline fishing effort was 8\% (east Pacific), 24\% (Oceania), 37\% (North Atlantic) and 38\% (southwest Indian Ocean) (Supplementary Table 10). Overlap patterns between ocean regions, and for species within regions, were not driven by the numbers of tags deployed (Supplementary Results and Discussion 2.1). Overlap varied across species and oceans, reflecting the heterogeneous distributions of space use by sharks and longline fishing activity (Extended Data Figs. 6, 7). For example, monthly spatial overlap, averaged across all oceans, ranged from $49 \%$ for the blue shark, down to $1.3 \%$ for the salmon shark. Among oceans, the overlap of space use by blue sharks - the pelagic shark most commonly caught by open-ocean longline fleets ${ }^{17}$ - was 
$76 \%$ in the North Atlantic, decreasing to $14 \%$ in the east Pacific (median overlap values given in Supplementary Tables 10, 11).

To estimate the potential exposure of sharks in different ocean regions to longline fishing effort, we calculated the mean monthly fishing effort that individual sharks were exposed to in each grid cell they occupied during a corresponding month, standardised to account for variations in individual track durations (hereafter termed fishing exposure index, FEI; see Methods). As expected across all oceans and species, sharks were exposed to highly variable longline fishing effort (Supplementary Table 10). Given this, we tested whether FEI was indicative of actual sharks captured and landed by fisheries. We compared the median monthly individual species FEI for North Atlantic shark species (the ocean for which we had the most species and tracks) with official records from the Food and Agriculture Organization of the United Nations (FAO) on mean annual North Atlantic landings of those species (Methods). We found a significant positive relationship between landings and individual species mean FEI (linear regression, $r^{2}$ $=0.45, n=8$ species/taxa group, $\left.F=6.72, F_{0.05(1), 1,7}=5.59, p<0.05\right)($ Extended Data Fig. 5), implying the index reflects fishing-induced shark mortality.

Hotspots of spatial overlap of shark relative density and longline fishing effort were evident for example in the Gulf Stream and stretching eastward to the Azores, western European shelf edge, west African upwelling, California Current (and white shark Café ${ }^{11}$ ), Agulhas Current, the southern Great Barrier Reef, and New Zealand shelf waters (Fig. 2c). This demonstrates that high fishing effort is focused on extensive shark hotspots globally (compare Supplementary Tables 6 and 12). Nonetheless, significant areas of the high seas used by pelagic sharks may exist that are largely free from AIS-monitored fishing activity of longline and purse seine vessels and which could be targeted for shark conservation measures (Supplementary Results and Discussion 2.7). Identifying such areas can only be addressed with the fisheryindependent distributions presented here. However, a general characteristic of large areas with 
low longline fishing activity was also one of lower shark densities $\left(<75^{\text {th }}\right.$ percentile of relative density; Fig. 2a), indicating sharks were not remaining in these areas but moving through them, potentially as part of foraging excursions or migrations for reproduction ${ }^{9,11}$. The lower relative density of sharks suggests lower productivity - supported by our modelling results (model 1; Extended Data Fig. 3) - and consequently poorer fishing opportunities, which may explain the apparent low fishing effort. The results also show that very few large hotspots of space use by pelagic sharks occurred in areas free from AIS fishing vessels, particularly longline and purse seine gears (Fig. 2c; Extended Data Fig. 2c, d).

\section{Determining spatial risk to sharks from fishing}

The extent of spatial overlap between shark relative density distribution and longline fishing effort indicates which species are more at risk from fishing and how this risk is distributed (Fig. 3). Since we demonstrate that a large proportion of shark fishing mortality as represented by landings is related to longline fishing effort in shark space use areas, it follows that sharks having both high fishing overlap and FEI (greater susceptibility) will be at greater risk of capture than those with low overlap and low FEI (Fig. 3). We found the main commercially valuable pelagic sharks were grouped within the highest potential risk zone in the North Atlantic and east Pacific (blue and shortfin mako sharks) (Fig. 3a,b; see Supplementary Results and Discussion 2.5 for significance tests and results for other species). In the North Atlantic, shortfin mako and blue sharks were at significantly greater risk compared to other tracked sharks because mean monthly space use overlap of $62 \%$ (median, $71 \%$ ) and $76 \%$ (median, 81\%) respectively, co-occurred with high mean FEI (Fig. 3a; Extended Data Figs. 6,7; Supplementary Table 10). However, exposure risk varied between oceans because although spatial overlap of blue shark remained relatively high in the southwest Indian Ocean and for blue and shortfin mako sharks in Oceania (mean, 18-47\%; median, 11-33\%; Supplementary Table 10), individual species FEI means were lower in those overlapping areas (Fig. 3a, c, d). 
Among sharks generally considered less commercially valuable, including tiger and bull sharks, we found risk from longlines was high in some but not all regions. Bull sharks used spatially limited near-shore habitats in tropical regions within the southwest Indian Ocean, and in those areas they were at increased risk due to high mean overlap (94\%) and high mean FEI (Fig. 3c; Supplementary Table 10). This greater susceptibility could lead to high localised catches, which, if replicated elsewhere, could explain why bull sharks are one of the ten most commonly traded species in the Hong Kong fin market ${ }^{24}$. In contrast, tiger sharks were exposed to lower overlap and lower mean FEI in all ocean areas except Oceania, where they were within the highest potential risk zone (Fig. 3a-d; Supplementary Results and Discussion 2.5, 2.6).

High risk was evident for internationally protected sharks under CITES (Convention on International Trade in Endangered Species) Appendix II and RFMO regulations. The porbeagle shark (IUCN Red List Endangered globally) and white shark (Vulnerable globally) have low population sizes compared to historic levels (Supplementary Table 2). In the North Atlantic and Oceania we found porbeagle in the highest risk zone (Fig. 3a,d), indicating high potential for incidental bycatch mortality. White sharks were in the highest risk zone in all oceans where they were tracked with mean spatial overlap ranging from $15 \%$ (east Pacific; median, 13\%) to 64\% (southwest Indian Ocean; median 65\%), except the North Atlantic where mean FEI was just below the average FEI for all species (Fig. 3; Supplementary Table 10). Our results showing high risk for porbeagle and white sharks from longlining across broad regions highlight the need for continued protection - including sufficient scientific observer coverage on vessels to underpin accurate data reporting - so that stock rebuilding can continue ${ }^{25}$, which for porbeagle is estimated to take a further 30 years ${ }^{18}$.

Decreasing the grid cell size in spatial analyses can lead to concomitant decreases in percentage spatial overlap estimates ${ }^{19}$, which could potentially affect the species risk exposure patterns we 
found. However, a grid-cell size analysis showed that the patterns of species occurrence within the high or low risk zones remained remarkably consistent irrespective of the spatial scale at which they were observed (Extended Data Fig. 4), or the subset of tracking years analysed (Extended Data Figs. 8, 9; Supplementary Results and Discussion 2.4).

\section{Temporal variation in risk}

The highest levels of exposure risk of sharks to longline fisheries were not constant through time but varied seasonally as shark and fishing vessel space use shifted in relation to each other (Fig. 4; Extended Data Fig. 10). Overall for species with sufficient data (plotted in Fig. 4), the mean monthly overlap of species space use with mean FEI showed sharks spent 4-6 months per year in the lowest risk zone and 2-6 months in the highest, with differing patterns of changing risk from fishing evident across species (Fig. 4). For example, highest risk for southwest Indian Ocean white and North Atlantic blue sharks occurred at discrete times in the year. For Indian Ocean white sharks, this pattern arises from long-range seasonal movements (Dec-Feb, Jun/Jul, Oct) into annually persistent areas with high mean FEI. For blue sharks, the discrete pattern appears driven by sharks and longline vessels co-occurring maximally in boreal winter and summer, with lower exposure risk occurring in boreal spring and autumn as sharks migrate north before returning south ${ }^{5}$. Longline fisheries also made this seasonal south-northsouth movement, but lagged behind movements of blue sharks and thus exhibited lower mean overlap and FEI during those times (Extended Data Fig. 10a-d). Similarly, annual risk patterns of east Pacific white and Australian tiger sharks were driven by migratory behaviour, with highest risk occurring for three consecutive months in boreal (white) and austral (tiger) spring as sharks arrive in areas with higher than average exposure to longline fishing effort (Fig. 4c, e). In contrast, shortfin mako sharks in the North Atlantic were exposed to high mean overlap ( $60 \%)$ and high mean FEI continually through the boreal summer and autumn (Jul-Oct), 
principally due to occupation of a space use hotspot located where the Gulf Stream and Labrador Current converge that results in persistent high overlap with high longline effort (Fig. 4b; Extended Data Fig. 10e-h). Shortfin mako and vessel tracking indicates that fisheryinduced mortality within this hotspot is therefore likely to be high. This was confirmed by the high overall return rate of satellite tags $(19.3 \%)$ attached to Atlantic shortfin makos $(n=119$ tags; tracking duration: mean $\pm \mathrm{SD}=161.5 \mathrm{~d} \pm 156.9$; median $=109 \mathrm{~d}$ ) that were returned to us after sharks were captured by Atlantic longline fleets during the study. To our knowledge, this is the highest species-specific return rate for sharks yet recorded on an ocean scale, as opposed to regional scale, study ${ }^{26,27}$ (Fig. 2c; Supplementary Table 13; Supplementary Results and Discussion 2.6).

\section{Discussion}

Our results show that globally important habitat areas for threatened pelagic sharks overlap significantly with industrial fishing activity in both space and time. Given the high fishing effort in hotspots of many species for significant portions of the year, and the very few tracked hotspots free from exploitation, our study reveals exposure risk of sharks to fisheries in the high seas is spatially extensive - stretching across entire ocean-scale population ranges for some species. Overall, the patterns suggest a future with limited spatial refuge from industrial longline fishing effort that is currently centred on ecologically important oceanic shark hotspots. The distribution maps reported here are, therefore, a first but essential underpinning for a conservation blueprint for pelagic sharks in the high seas. Our study highlights the scale of fishing overlap with shark hotspots and argues for more effective and timely monitoring, reporting and management of pelagic sharks as a result. To enhance the recovery of vulnerable species, one solution is designation of large-scale marine protected areas (MPAs) ${ }^{28}$ around ecologically important space use hotspots of pelagic sharks ${ }^{23}$, notwithstanding the need for 
more complete reporting of catch data with enforcement to support stricter conventional management by catch prohibitions, quotas or minimum sizes ${ }^{5,16}$. This study outlines shark hotspot locations where AIS-monitored fishing effort appears currently relatively low, which is where shark conservation could be maximized, while minimizing impact on fishing activity not directed at sharks (Supplementary Results and Discussion 2.6, 2.7). Although it would be challenging to develop a legally binding treaty for managing high seas fauna ${ }^{20}$, burgeoning technology for global surveillance and enforcement now offers valuable additional options for a step change in ocean management ${ }^{6,29}$.

Satellite monitoring of marine megafauna ${ }^{1,5,11,30}$, oceanographic features (eddies, fronts) ${ }^{6,23}$ and global fishing vessel distributions ${ }^{19}$ could provide signals of shifting space use by wide-ranging sharks and other marine megafauna due to environmental changes that, in turn, could inform designation of new temporary time-area closures to industrial fishing ${ }^{6}$ and tracking of fishers' displacement activities ${ }^{20}$. The potential of near real time, synoptic measurements of marine megafauna, fishing activity and the marine environment, particularly given the remoteness and vast extent of the high seas, suggests technology-led conservation measures will be crucial tools for reversing the observed declines in iconic ocean predators ${ }^{3}$ such as pelagic sharks ${ }^{12-}$ ${ }^{14,29}$. Conservation technology could develop in the future toward incorporation of adaptive management strategies ${ }^{6,29}$ that are actionable in real time to assess risks in the overlap between fishing vessels and sharks across the global ocean.

\section{Online content}

The Methods, including statements of data availability and Nature Research reporting summaries, along with additional references are available in the online version of this paper.

1. Hays, G.C. et al. Key questions in marine megafauna movement ecology. Trends Ecol. Evol. 31, 463-475 (2016). 
2. Lewison, R.L. et al. Global patterns of marine mammal, seabird, and sea turtle bycatch reveal taxa-specific and cumulative megafauna hotspots. Proc. Natl. Acad. Sci. USA 111, 52715276 (2014).

3. McCauley, D.J., Pinsky, M.L., Palumbi, S.R., Estes, J.A. Joyce, F.H., Warner, R.R. Marine defaunation: Animal loss in the global ocean. Science 347, 1255641 (2015).

4. Worm, B., Sandow, M., Oschlies, A., Lotze, H., Myers, R.A. Global patterns of predator diversity in the open oceans. Science 309, 1365-1369 (2005).

5. Queiroz, N. et al. Ocean-wide tracking of pelagic sharks reveals extent of overlap with longline fishing hotspots. Proc. Natl. Acad. Sci. USA 113, 1582-1587 (2016).

6. Scales, K.L. et al. Fisheries bycatch risk to marine megafauna is intensified in Lagrangian coherent structures. Proc. Natl. Acad. Sci. USA 115, $7362-7367$ (2018).

7. O’Connor, S., Ono, R., Clarkson, C. Pelagic fishing at 42,000 years before the present and the maritime skills of modern humans. Science 334, 1117-1121 (2011).

8. Tickler, D., Meeuwig, J.J., Palomares, M.-L., Pauly, D., Zeller, D. Far from home: Distance patterns of global fishing fleets. Sci. Adv. 4, eaar3279 (2018).

9. Lea, J.S.E. et al. Repeated, long-distance migrations by a philopatric predator targeting highly contrasting ecosystems. Sci. Rep. 5, 11202 (2015).

10. Guzman, H.M., Comez, C.G., Hearn, A., Eckert, S.A. Longest recorded trans-Pacific migration of a whale shark. Mar. Biodivers. Rec. 11, 8, https://doi.org/10.1186/s41200018-0143-4 (2018).

11. Block, B.A. et al. Tracking apex marine predator movements in a dynamic ocean. Nature 475, 86-90 (2011). 
Nature 572, 461-466 (2019) doi: 10.1038/s41586-019-1444-4 (Accepted version)

12. Worm, B. et al. Global catches, exploitation rates, and rebuilding options for sharks. Mar. Policy 40, 194-204 (2013).

13. Baum, J.K. et al. Collapse and conservation of shark populations in the North-west Atlantic. Science 299, 389-392 (2003).

14. Ferretti, F., Worm, B., Britten, G.L., Heithaus, M.R., Lotze, H.K. Patterns and ecosystem consequences of shark declines in the ocean. Ecol. Lett. 13, 1055-1071 (2010).

15. Oliver, S., Braccini, M., Newman, S.J., Harvey, E.S. Global patterns in the bycatch of sharks and rays. Mar. Policy 54, 86-97 (2015).

16. Campana, S.E. Transboundary movements, unmonitored fishing mortality, and ineffective international fisheries management pose risks for pelagic sharks in the Northwest Atlantic. Can. J. Fish. Aquat. Sci. 73, 1599-1607 (2016).

17. International Commission for the Conservation of Atlantic Tunas (ICCAT). Report of the 2017 ICCAT Shortfin Mako Assessment Meeting (Madrid, Spain, 2017); (<https://www.iccat.int/Documents/Meetings/Docs/2017_SMA_ASS_REP_ENG.pdf〉)

18. International Commission for the Conservation of Atlantic Tunas (2017) Report of the Standing Committee on Research and Statistics (SCRS), Doc. No. PLE 104/2017. (<https://www.iccat.int/Documents/Meetings/Docs/2017_SCRS_REP_ENG.pdf>)

19. Kroodsma, D.A. et al. Tracking the global footprint of fisheries. Science 359, 904-908 (2018). See also Response to Comment; Science 361, eaat7789 (2018).

20. McCauley, D.J. et al. Marine governance: Ending hide and seek at sea. Science 351, 11481150 (2016). 
Nature 572, 461-466 (2019) doi: 10.1038/s41586-019-1444-4 (Accepted version)

21. Shepperson, J.L., Hintzen, N.T., Szostek, C.L., Bell, E., Murray, L.G., Kaiser, M.J. A comparison of VMS and AIS data: the effect of data coverage and vessel position recording frequency on estimates of fishing footprints. ICES J. Mar. Sci. 75, 988-998 (2018).

22. Sala, E. et al. The economics of fishing the high seas. Sci. Adv. 4, eaat2504 (2018).

23. Scales, K.L., Miller, P.I., Hawkes, L.A., Ingram, S.N., Sims, D.W., Votier, S.C. On the front line: frontal zones as priority at-sea conservation areas for mobile marine vertebrates. J. Appl. Ecol. 51, 1575-1583 (2014).

24. Fields, A.T. et al. Species composition of the international shark fin trade assessed through a retail-market survey in Hong Kong. Conserv. Biol. 32, 376-389 (2018).

25. Curtis, T.A. et al. Seasonal distribution and historic trends in abundance of white sharks, Carcharodon carcharias, in the Western North Atlantic Ocean. PLoS One 9, e99240 (2014).

26. Kohler, N.E., Turner, P.A. Shark tagging: a review of conventional methods and studies. Environ. Biol. Fish. 60, 191-223 (2001).

27. Byrne, M.E. et al. Satellite telemetry reveals higher fishing mortality rates than previously estimated, suggesting overfishing of an apex marine predator. Proc. R. Soc. B 284, 20170658 (2017).

28. O'Leary, B.C. et al. Addressing criticisms of large-scale marine protected areas. BioScience 68, 359-370 (2018).

29. Hays, G.C. et al. Translating marine animal tracking data into conservation policy and management. Trends Ecol. Evol. 34, 459-473 (2019). 
Nature 572, 461-466 (2019) doi: 10.1038/s41586-019-1444-4 (Accepted version)

30. Sequeira, A.M.M. et al. Convergence of marine megafauna movement patterns in coastal and open oceans. Proc. Natl Acad. Sci. USA 115, 3072-3077 (2018).

Acknowledgements. We thank all involved in fieldwork and data collection; full details are given in Supplementary Information. Data analysis was funded in part by the Marine Biological Association (MBA) and the UK Natural Environment Research Council (NERC) (NE/R00997X/1) (to D.W.S.), with additional research support from the Save Our Seas Foundation and the NERC Oceans 2025 Strategic Research Programme in which D.W.S. was a principal investigator. D.W.S. was supported by an MBA Senior Research Fellowship, N.Q. by European Regional Development Fund (FEDER) via the Programa Operacional Competitividade e Internacionalização (COMPETE), National Funds via Fundação para a Ciência e a Tecnologia (FCT) under PTDC/MAR/100345/2008 and COMPETE FCOMP-010124-FEDER-010580 (to N.Q. and D.W.S.), Norte Portugal Regional Operational Programme (NORTE 2020) under the PORTUGAL 2020 Partnership Agreement through the European Regional Development Fund (ERDF) under project MarInfo (NORTE-01-0145-FEDER000031). Additional support was provided by an FCT Investigator Fellowship IF/01611/2013 (N.Q.), FCT Doctoral Fellowship PD/BD/52603/2014 (M.V.), PTDC/MAR-BIO/4458/2012, Xunta de Galicia - Isabel Barreto Program 2009-2012 (G.M.), Australian Research Council (ARC) grant DE170100841 and operational funds from the Australian Institute for Marine Science (AIMS) (both to A.M.M.S.). We thank Stanford University, the Tagging of Pacific Predators programme and Global Fishing Watch for making data freely available. We thank Marc Dando for creating the shark images. This research contributes to the Global Shark Movement Project (GSMP).

Author Contributions. GSMP is coordinated by D.W.S. N.Q. and D.W.S. conceived the study, N.Q., N.E. Humphries and D.W.S. designed the study, and all authors contributed to animal tagging, fieldwork, data collection and/or contribution of tools; full details given in 
Nature 572, 461-466 (2019) doi: 10.1038/s41586-019-1444-4 (Accepted version)

Supplementary Information. N.Q., N.E. Humphries, A.C., M.V., I.C., A.M.M.S., L.L.S., S.J.S. and D.W.S. analysed collated data. D.W.S. drafted the paper with contributions from N.Q., N.E. Humphries and A.M.M.S. All authors contributed to subsequent drafts.

Competing interests The authors declare no competing interests.

\section{Additional Information}

Extended Data is available for this paper.

Supplementary Information is available for this paper.

Reprint and permissions information is available

Correspondence and request for materials should be addressed to D.W.S. 

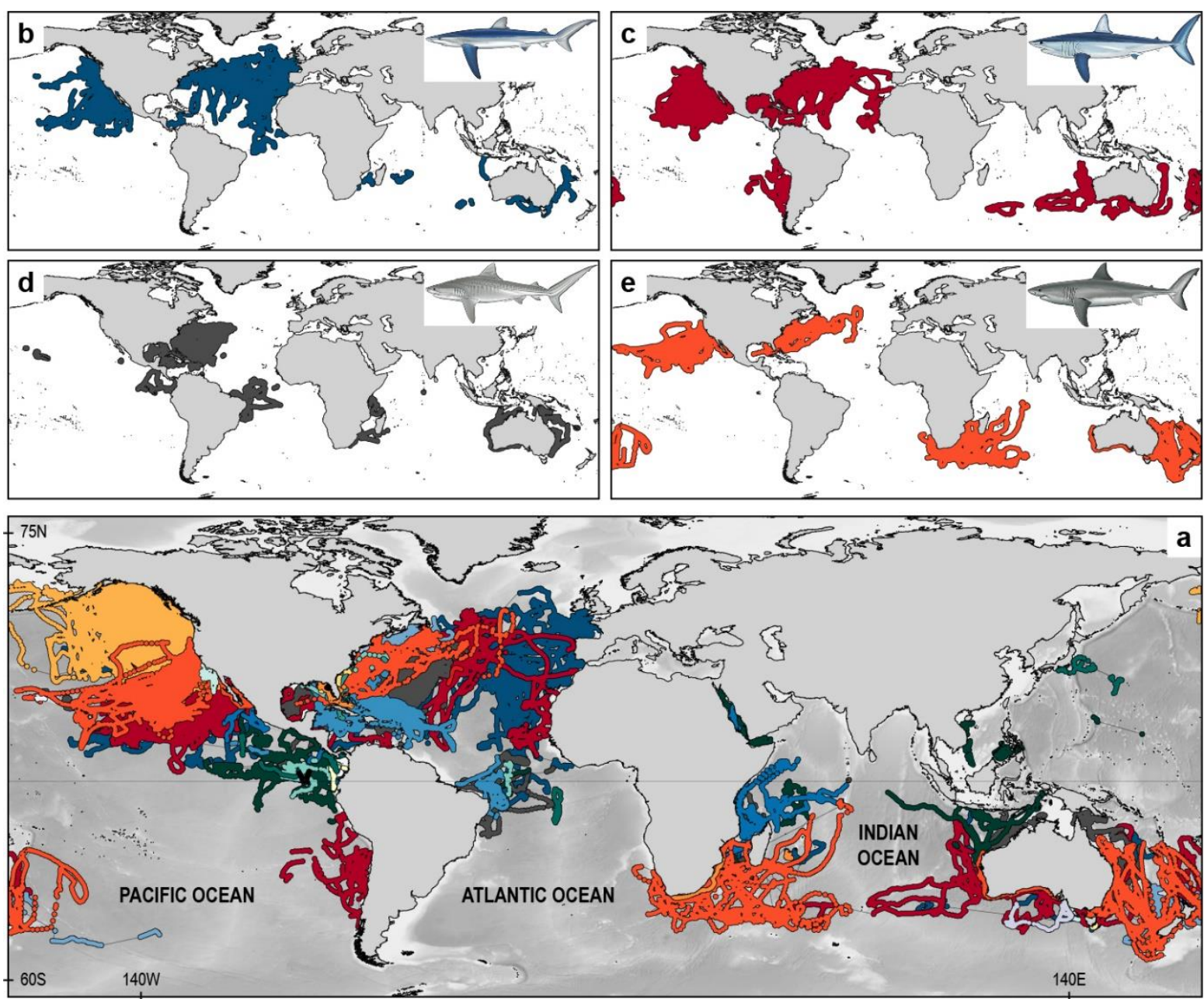

Galeocerdo cuvier (GCU)*

- Prionace glauca (PGL)*

Carcharhinus falciformis (CFA)

- Carcharhinus longimanus (CLO)

Lamna nasus (LNA)

Sphyrna zygaena (SPH)

Carcharhinus brachyurus

Carcharhinus plumbeus
Isurus oxyrinchus (IOX)*

Isurus paucus

- Carcharodon carcharias (CCA)*

- Carcharhinus leucas (CLE)

Lamna ditropis (LDI)

Carcharhinus obscurus

Notorynchus cepedianus

Odontaspis ferox
Rhincodon typus (RTY)

- Carcharhinus galapagensis

Sphyrna mokarran (SPH)

Sphyrna lewini (SPH)

Alopias vulpinus

Alopias pelagicus

- Carcharhinus limbatus

Fig. 1. Movements of oceanic and neritic pelagic sharks. (a) Daily state-space model locations estimated from locations obtained via satellite transmitters deployed on 1,681 sharks from 23 species between 2002-2017. Extent of individual shark species space use areas are illustrated for the species with the greatest numbers of tags deployed across multiple ocean regions: blue Prionace glauca (b), shortfin mako Isurus oxyrinchus (c), tiger Galeocerdo cuvier (d), and white Carcharodon carcharias (e) sharks. Shark images created by M. Dando. 


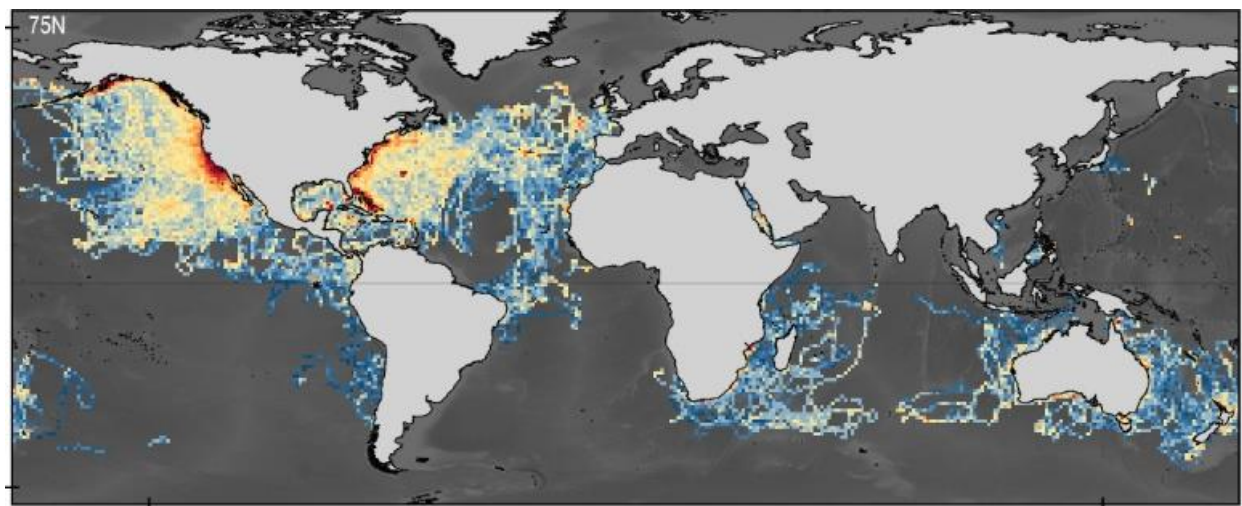

a Shark relative density

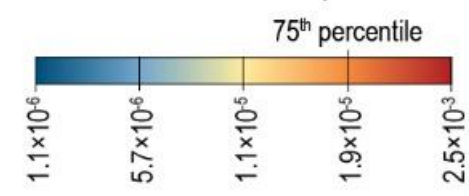

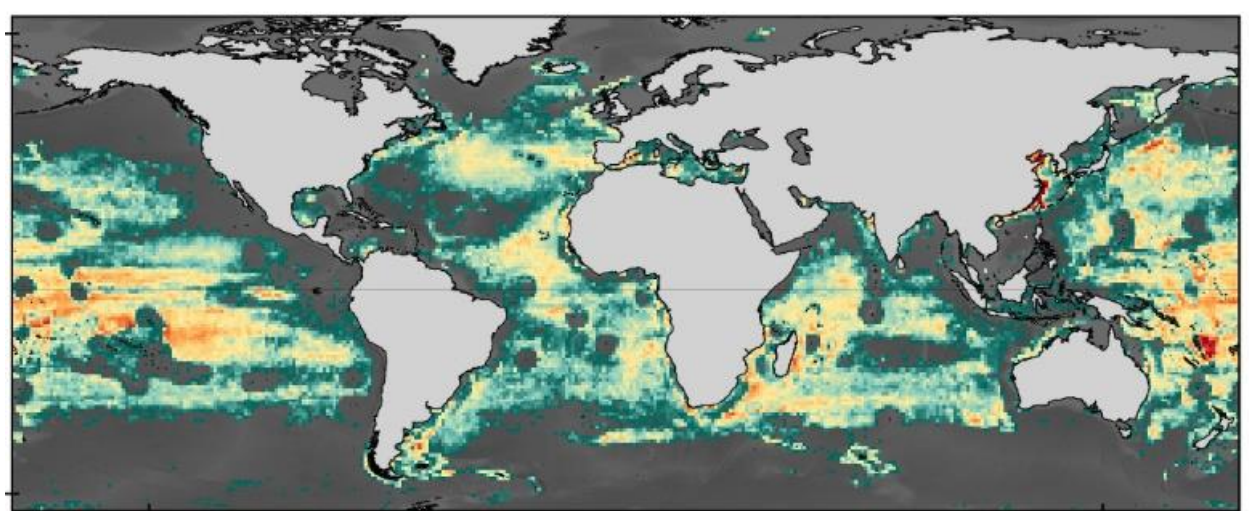

b Number of days fishing
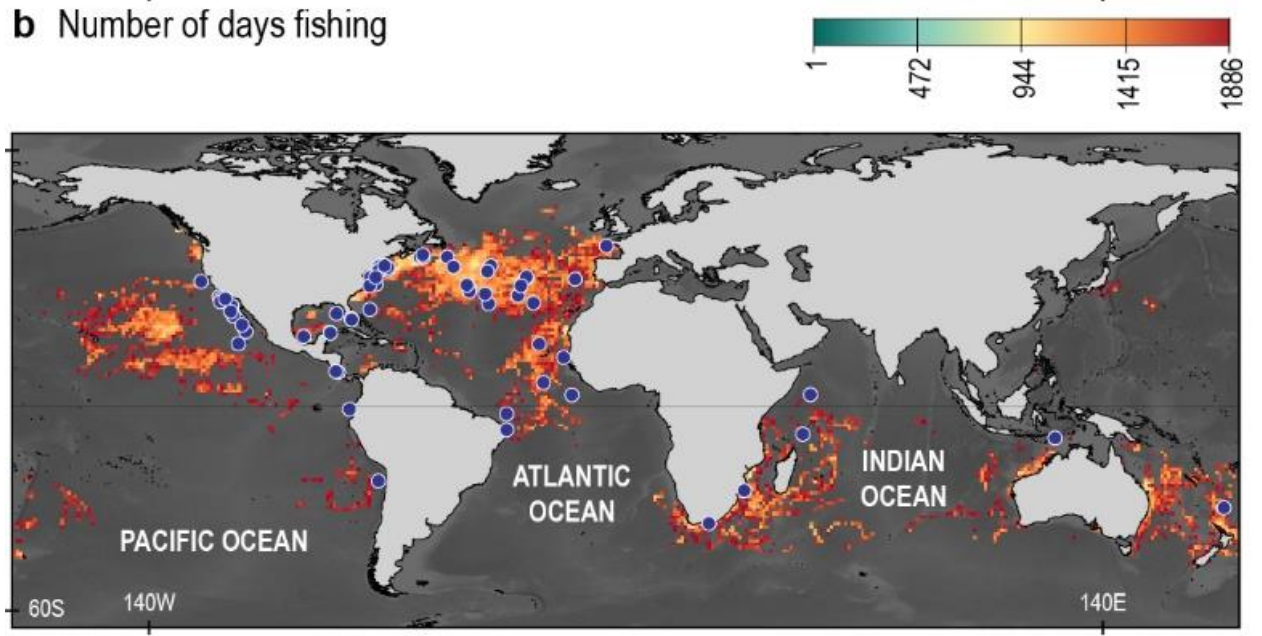

c Fishing exposure index

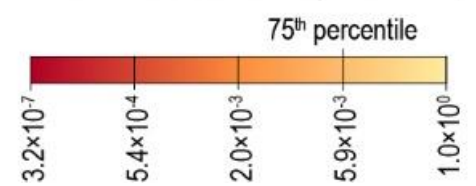

Fig. 2. Spatial distributions and overlap of sharks and longline fishing vessels. (a)

Distribution of the mean monthly weighted, normalized location density of tracked sharks in 1 $\times 1^{\circ}$ grid cells (shark hotspots were defined by cells with $\geq 75^{\text {th }}$ percentile of relative density) 
Nature 572, 461-466 (2019) doi: 10.1038/s41586-019-1444-4 (Accepted version)

(b) Mean annual distribution of fishing effort (mean days per grid cell) of AIS tracked longlining vessels in 2012-2016 (see Methods). (c) Distribution of the mean monthly overlap and level of fishing effort (days) sharks were exposed to in overlapping areas for all species within $1 \times 1^{\circ}$ grid cells (see Methods). Hotspots of spatial overlap of shark density and fishing effort were defined as cells with $\geq 75^{\text {th }}$ percentile of mean FEI. Blue circles denote locations where tagged sharks were caught by commercial fishers mainly using pelagic longlines and coastal nets. 


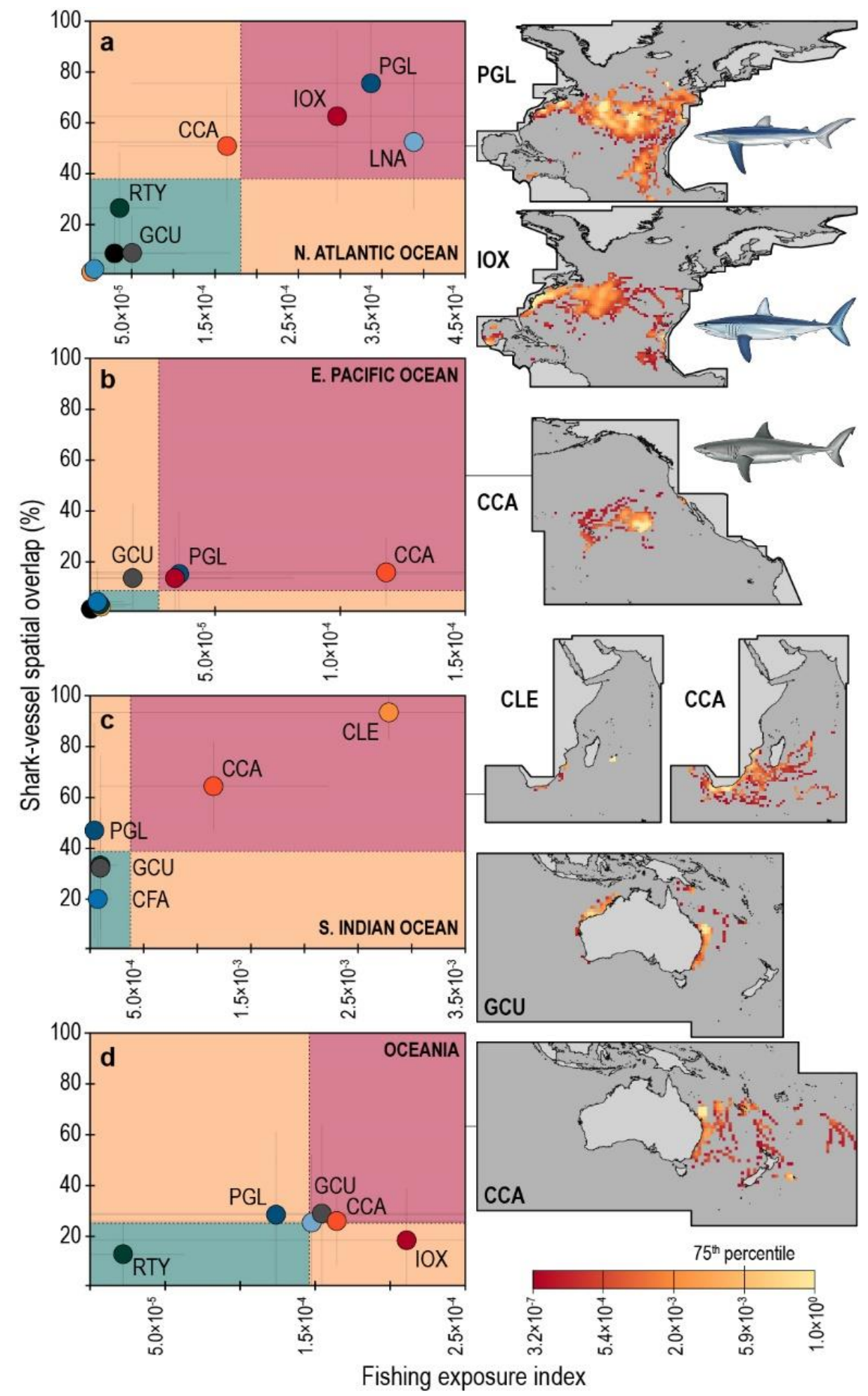

Fig. 3. Estimated exposure risk of sharks to capture by longline fishing activity. Plots (left) showing spatial overlap of sharks and longline fishing effort against species mean monthly fishing exposure index (FEI) indicate species subject to high overlap and FEI (higher than average overlap and FEI; higher risk red zone on plot) and those with lower overlap and FEI 
(lower than average overlap and FEI; lower risk green zone) for (a) North Atlantic, (b) eastern Pacific and (c) southern Indian oceans, and (d) for the Oceania region. Lines separating the coloured zones are fixed at the average values of spatial overlap ( $y$ axis) and FEI ( $x$ axis) for all species combined. For each ocean, the amount of fishing effort individual shark species were exposed to (mean FEI; see Methods for details) are given on right panels. Shark species identification codes (e.g. PGL) used on panels are given in Fig. 1. Error bars denote \pm one standard deviation of the mean. 


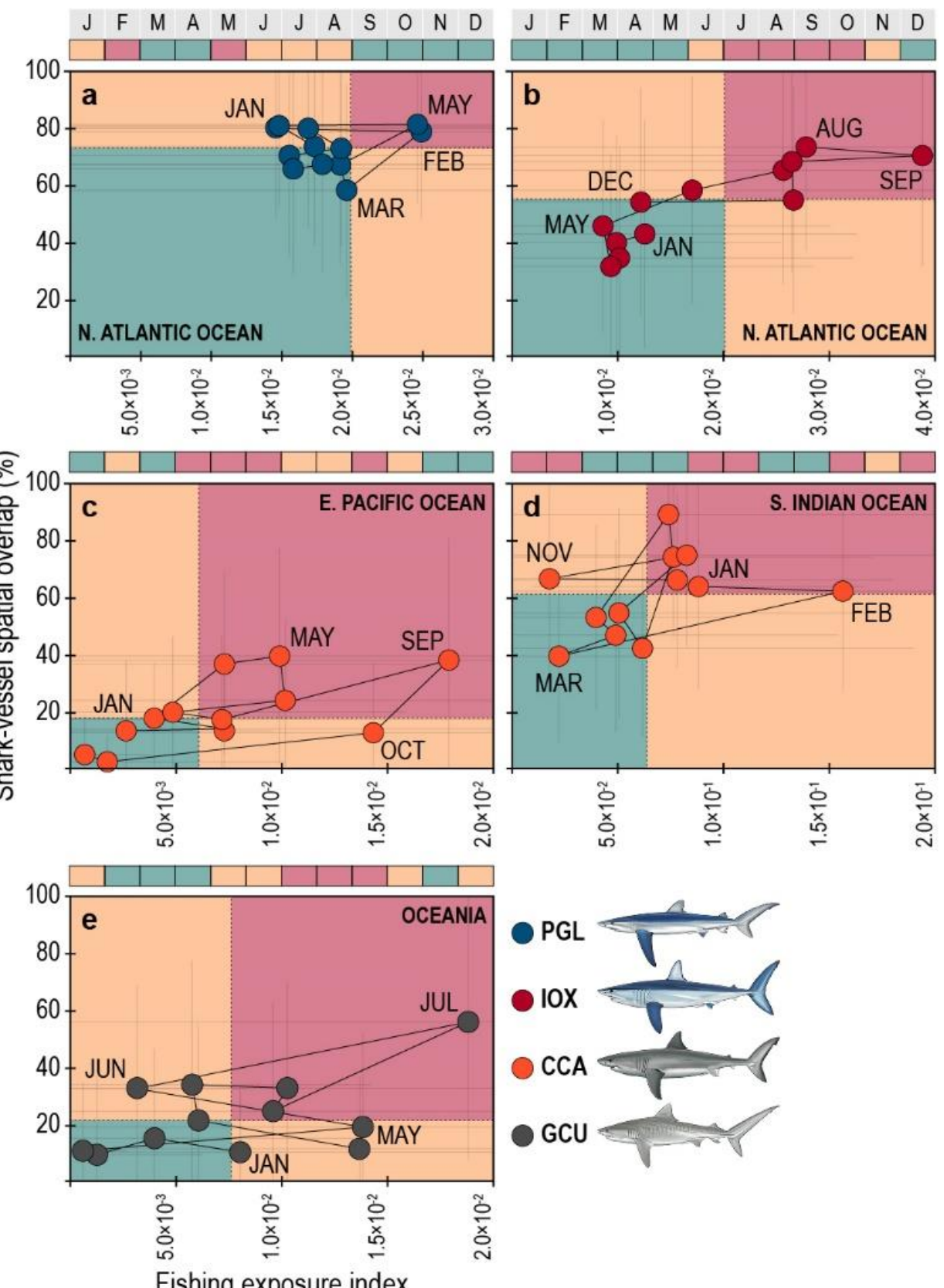

Fig. 4. Temporal changes in shark exposure risk to longline fishing. Monthly mean spatial overlap of sharks and longline fishing effort versus monthly mean FEI for all individuals of that species for the four most data-rich species in a relative year: (a) blue, (b) shortfin mako, $(\mathbf{c}, \mathbf{d})$ white, and (e) tiger sharks. Lines separating the coloured zones are fixed at the respective individual species average values of spatial overlap ( $y$ axis) and FEI ( $x$ axis) in a relative year. Horizontal bars denote months in different fishing exposure risk zones (red, highest risk; green, lowest). Error bars denote \pm one standard deviation of the mean. 

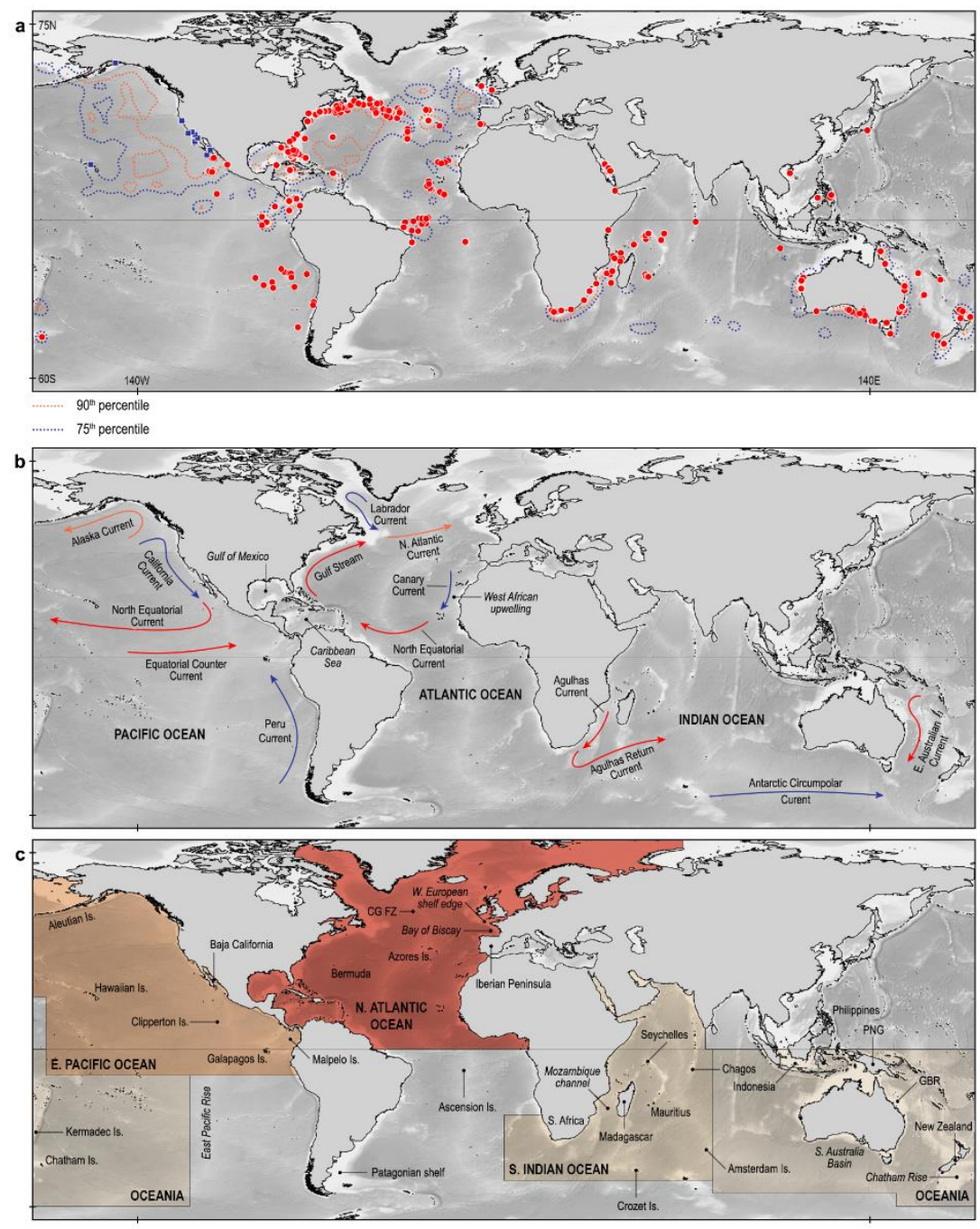

\section{Extended Data Fig. 1. The locations of shark tag deployment sites in relation to shark} space use hotspots, ocean currents, physical features and fishing areas. (a) Red circles denote the locations where satellite transmitters were attached and sharks released, and blue squares in the eastern Pacific denote annual median deployment locations of tags by the Tagging of Pacific Predators (TOPP) program (ref. 11). Shark space use hotspots are shown as the $75^{\text {th }}$ (blue dotted lines) and $90^{\text {th }}$ percentiles (red dotted lines) of the mean monthly relative density of estimated shark locations within $1 \times 1^{\circ}$ grid cells given in Fig. 2a. Schematic maps of major ocean currents (b) and physical features overlaid on FAO fishing areas (c) referred to in this paper. Coloured arrows in $\mathbf{b}$ denote thermal regime of currents, with warmer colours 
Nature 572, 461-466 (2019) doi: 10.1038/s41586-019-1444-4 (Accepted version)

indicating higher water temperature. Abbreviations in c denote: CGFZ, Charlie Gibbs Fracture Zone; GBR, Great Barrier Reef; PNG, Papua New Guinea. 

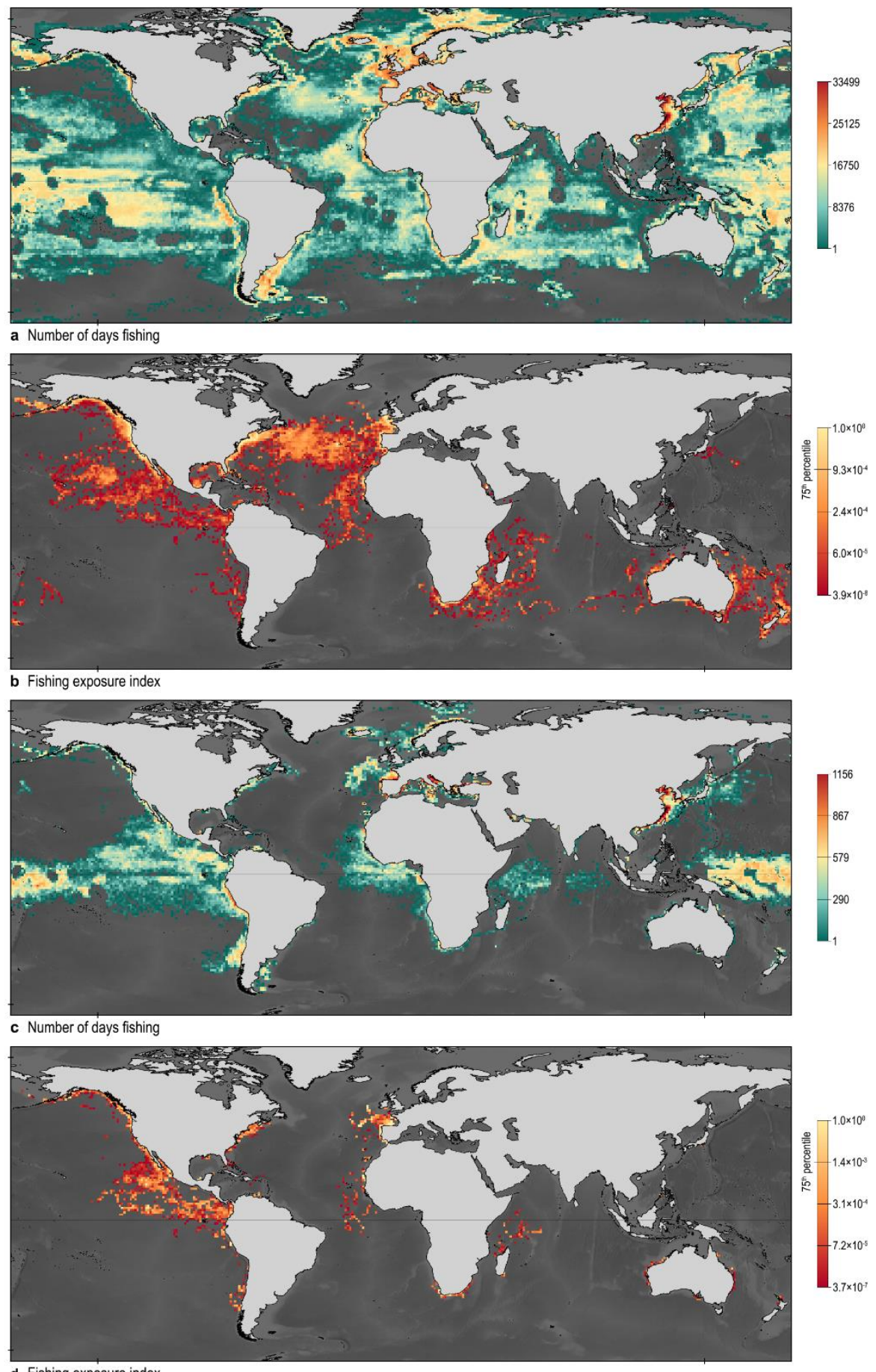

d Fishing exposure index

\section{Extended Data Fig. 2. Spatial distribution of fishing vessels and overlap with sharks. (a)}

Distribution of AIS tracked fishing vessels' effort (mean annual days spent per grid cell) between 2012 and 2016 (see Methods). (b) Distribution of the mean monthly overlap and level of all vessels' fishing effort (days) sharks were exposed to in overlapping areas for all species 
within $1 \times 1^{\circ}$ grid cells (see Methods). Spatial overlap hotspots were defined as $1 \times 1^{\circ}$ grid cells with $\geq 75^{\text {th }}$ percentile of mean FEI. Note the similar overlap pattern of sharks and all mapped AIS fishing vessels as that determined for sharks and longline vessels in Fig. 2c. (c) Distribution of AIS purse seine vessels' fishing effort using mean annual days spent per grid cell between 2012 and 2016 (see Methods). (d) Distribution of the mean monthly overlap and level of purse seine vessels' fishing effort (days) sharks were exposed to in overlapping areas for all species within $1 \times 1^{\circ}$ grid cells (see Methods). Spatial overlap hotspots were defined as $1 \times 1^{\circ}$ grid cells with $\geq 75^{\text {th }}$ percentile of mean FEI. 


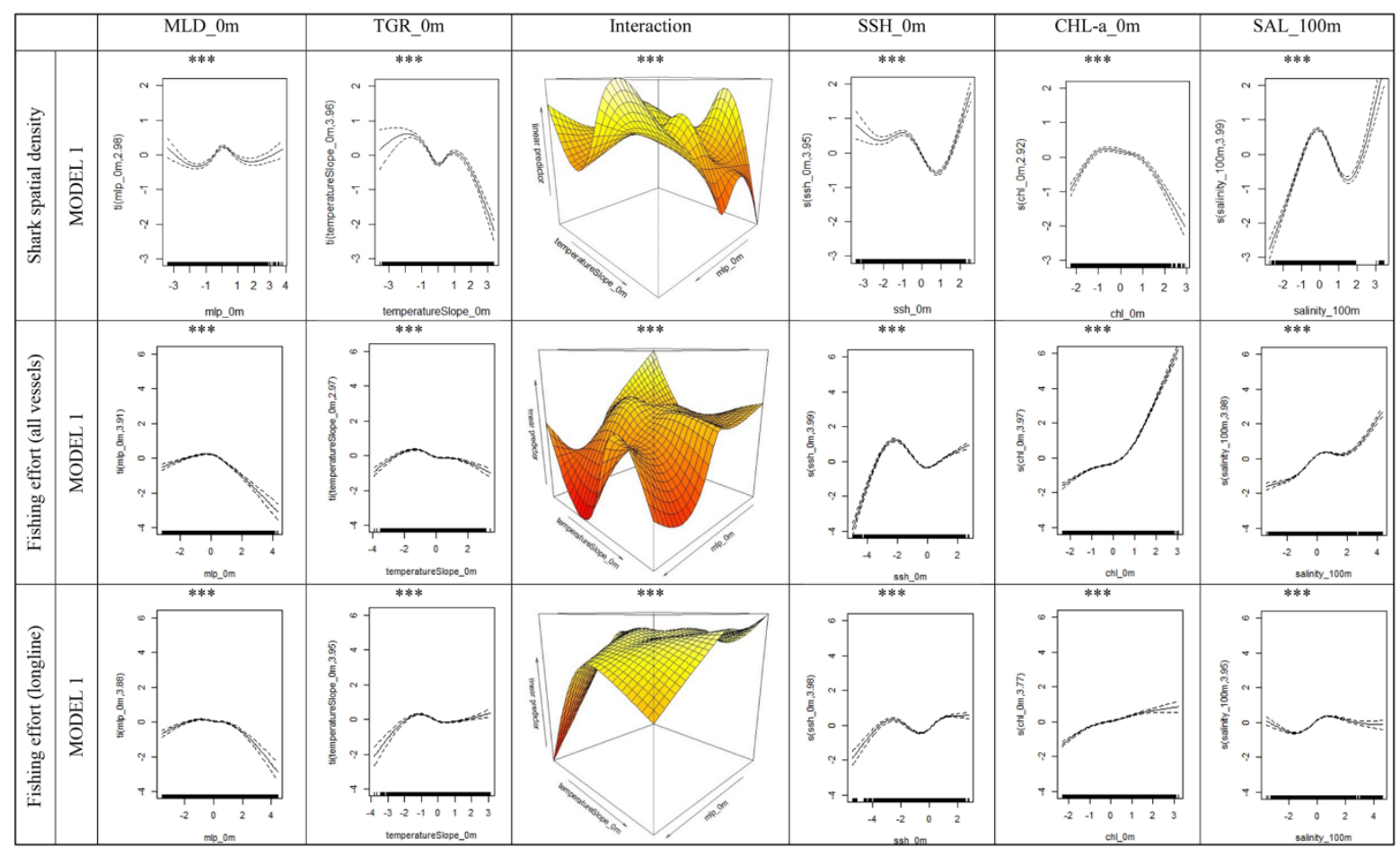

Extended Data Fig. 3. Environmental modelling results. Estimated relationships between mean monthly relative density of all sharks (top panel) and AIS fishing effort of all vessels (middle panels) and longlines only (bottom panels) with all environmental variables in the highest ranked (Model 1) of the generalised additive models (GAM) tested. Third column shows the interaction results between the two variables described in the first and second columns. Asterisks indicate significance level for each smooth term included in the GAM, representing $p<0.001(* * *)$. 


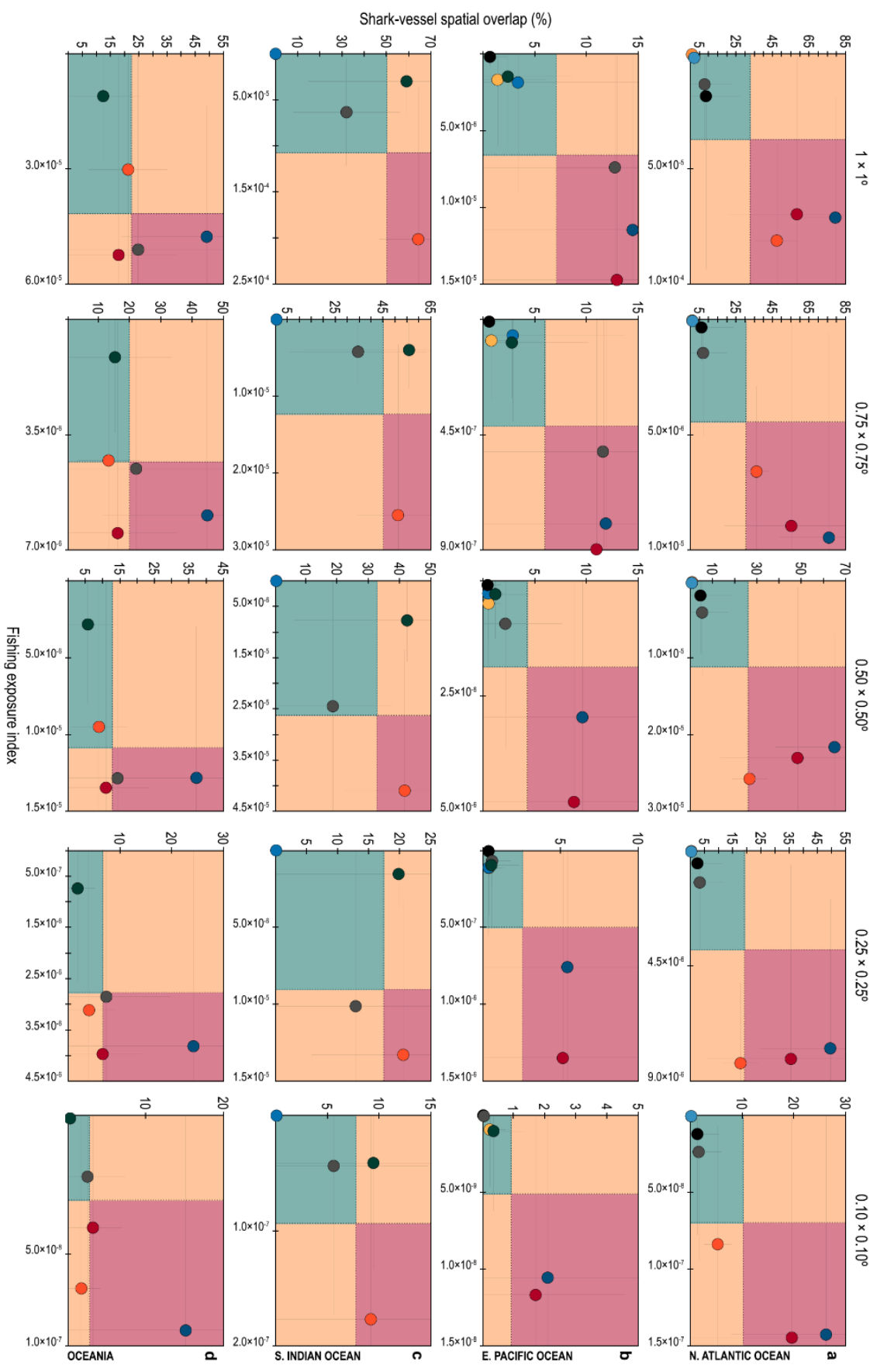

\section{Extended Data Fig. 4 Effect of grid cell size on risk exposure patterns of sharks to longline}

fisheries. (a) North Atlantic, (b) east Pacific, (c) southwest Indian oceans and (d) Oceania. Note that regardless of grid cell size at which the individual species mean spatial overlap and FEI were calculated the species occurring in the highest (red) and the lowest risk zones (green) remain remarkably conserved, indicating a general pattern not dependent on the scale at which 
Nature 572, 461-466 (2019) doi: 10.1038/s41586-019-1444-4 (Accepted version)

these data were analysed. Shark-species identification codes are given in Fig. 1. Error bars are \pm 1 S.D. An additional comparison of $2 \times 2^{\circ}$ with $1 \times 1^{\circ}$ grid cell size is given in Supplementary Fig. 4. 


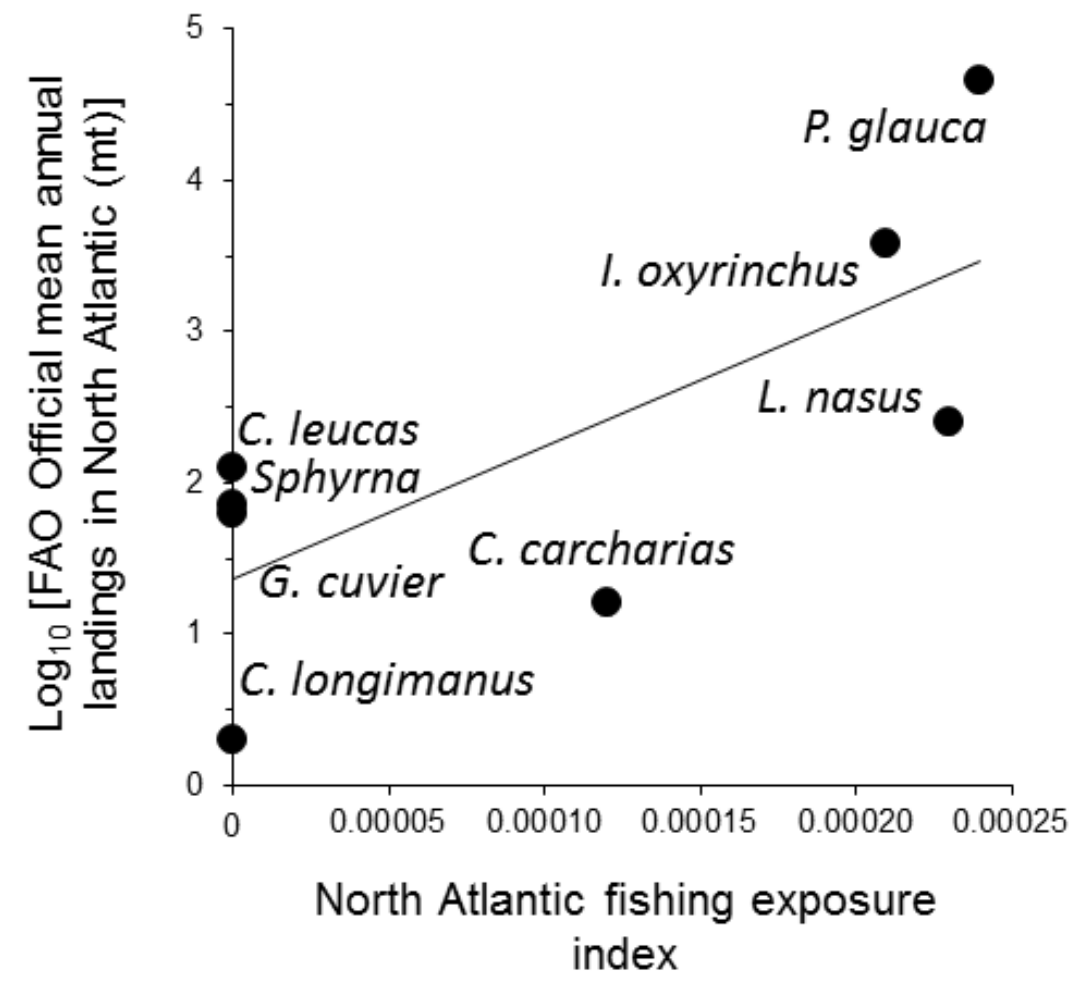

Extended Data Fig. 5. Relationship between North Atlantic fisheries'shark landings and shark density-longline fishing exposure index. Plot showing shark landings from the North Atlantic (mean, 2007-2016), extracted from the Food and Agriculture Organization of the United Nations (FAO) total capture production database, was dependent upon the North Atlantic longline fishing effort as estimated with the individual species FEI (70\% shark tracked, 2007-2017; AIS, 2012-2016) (see Methods). Using linear regression, we tested the null hypothesis $\left(H_{0}\right)$ that $\beta=0$ after normalising landings (in metric tonnes) by log transformation and for median FEI per species. Regression analysis gave the equation: $\log ($ landings $)=1.364$ +8732 FEI, with a regression coefficient $(b)$ standard error of 3369 . We computed $r^{2}=0.45$, $F=6.72$ and $F_{0.05(1), 1,7}=5.59$, therefore rejecting $H_{0}$ at the $5 \%$ level of significance with $p<$ 0.05. Full scientific names are given in Fig. 1. 

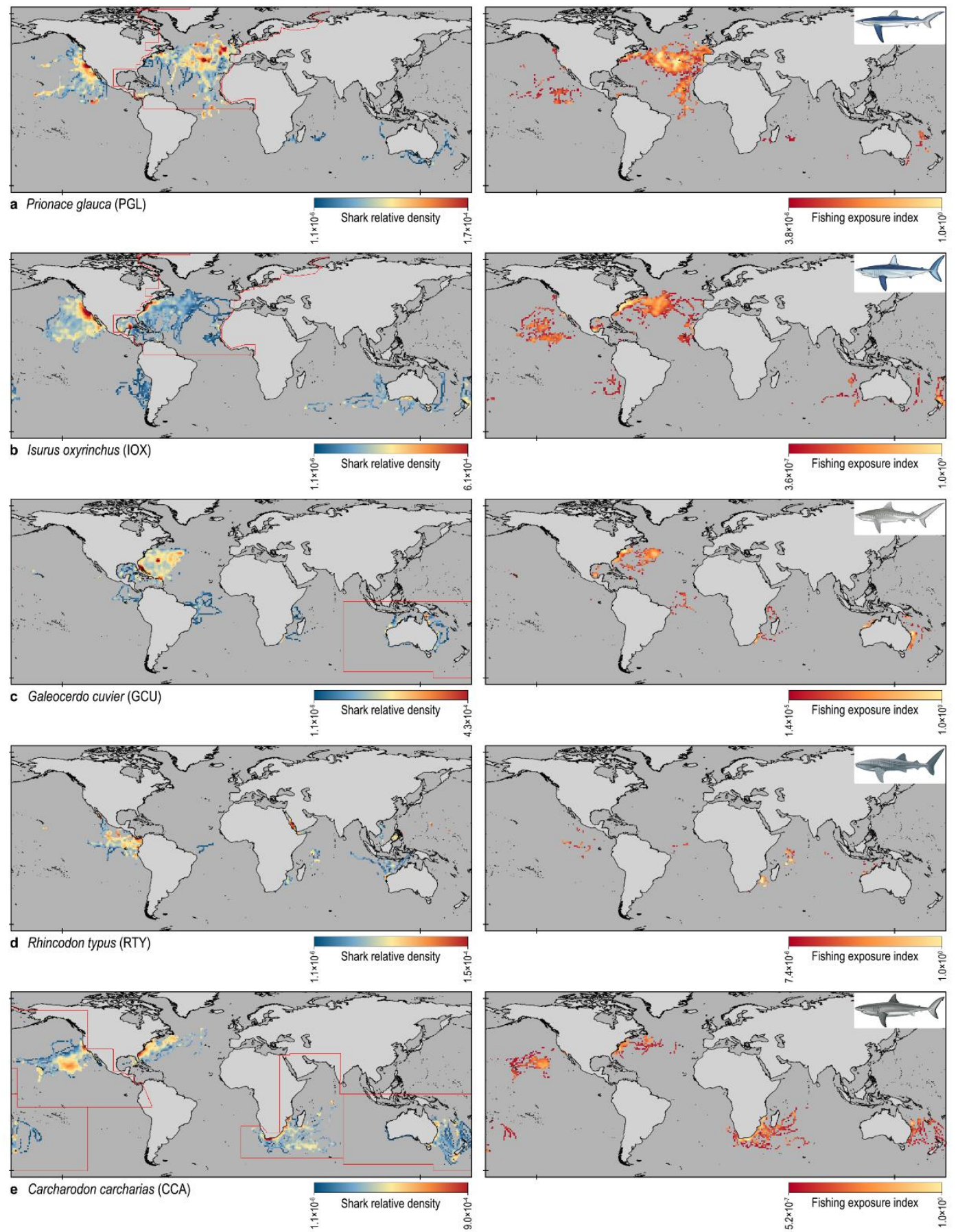

\section{Extended Data Fig. 6. Relative density and spatial overlap distributions for individual}

shark species. Mean monthly relative density of shark species (left panels) tracked in 20022017 in comparison with species mean FEI per grid cell for the 5 most data-rich species/taxa groups occurring in multiple oceans (right panels): (a) blue, Prionace glauca; (b) shortfin 
Nature 572, 461-466 (2019) doi: 10.1038/s41586-019-1444-4 (Accepted version)

mako, Isurus oxyrinchus; (c) tiger, Galeocerdo cuvier; (d) whale shark, Rhincodon typus; and (e) white, Carcharodon carcharias. Red boxes denote areas shown in Fig. 3. Shark images created by M. Dando. 

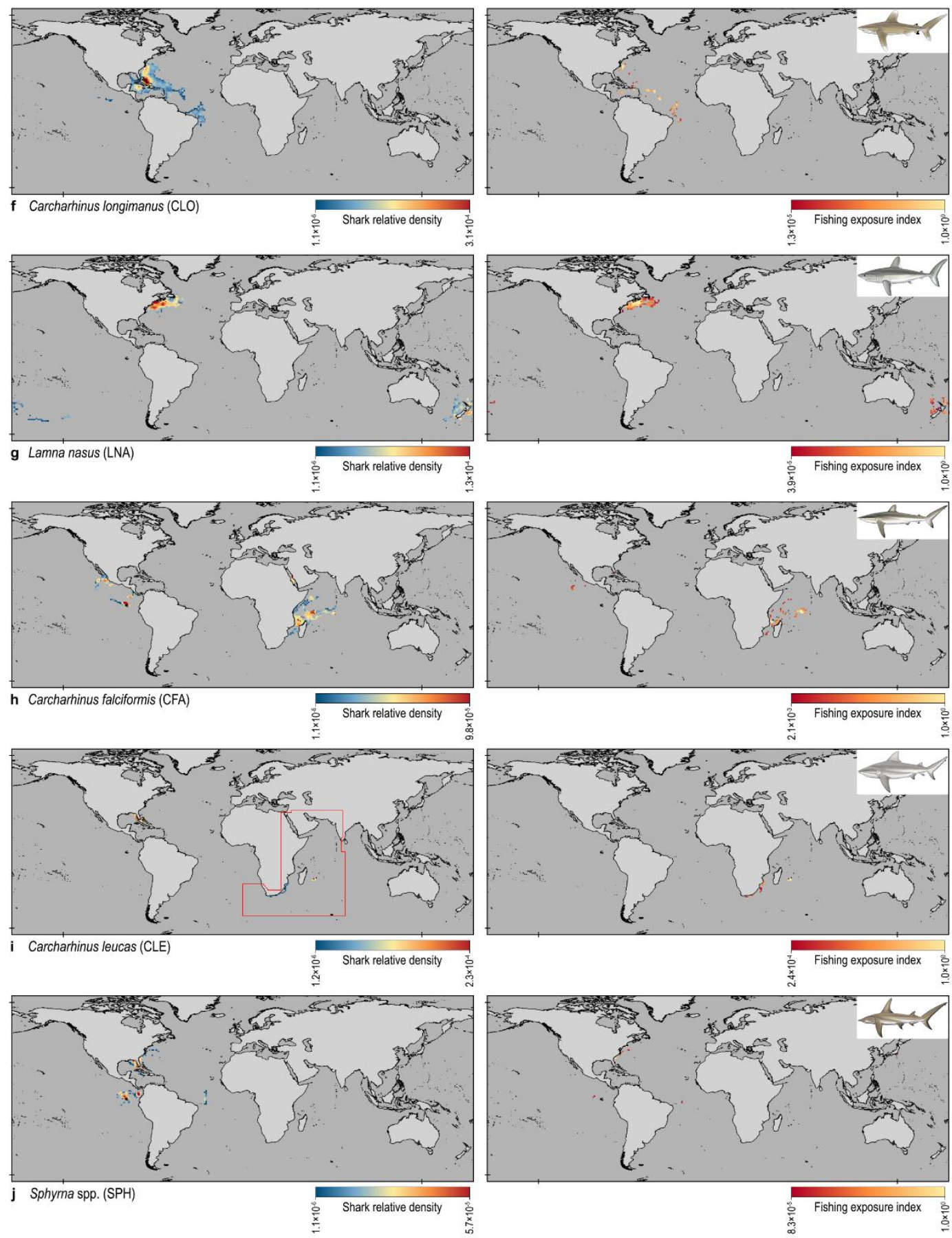

\section{Extended Data Fig. 7. Relative density and spatial overlap distributions for individual}

shark species (continued). Mean monthly relative density of shark species (left panels) tracked in 2002-2017 in comparison with species mean FEI per grid cell for the next 5 most data-rich species/taxa groups occurring in multiple oceans (right panels): (f) oceanic whitetip, 
Nature 572, 461-466 (2019) doi: 10.1038/s41586-019-1444-4 (Accepted version)

Carcharhinus longimanus; (g) porbeagle, Lamna nasus; (h) silky, Carcharhinus falciformis; (i) bull, Carcharhinus leucas; and (j) hammerhead sharks, Sphyrna spp. (comprising: scalloped, S. lewini; great, S. mokarran; and smooth, S. zygaena). Shark images created by M. Dando. 

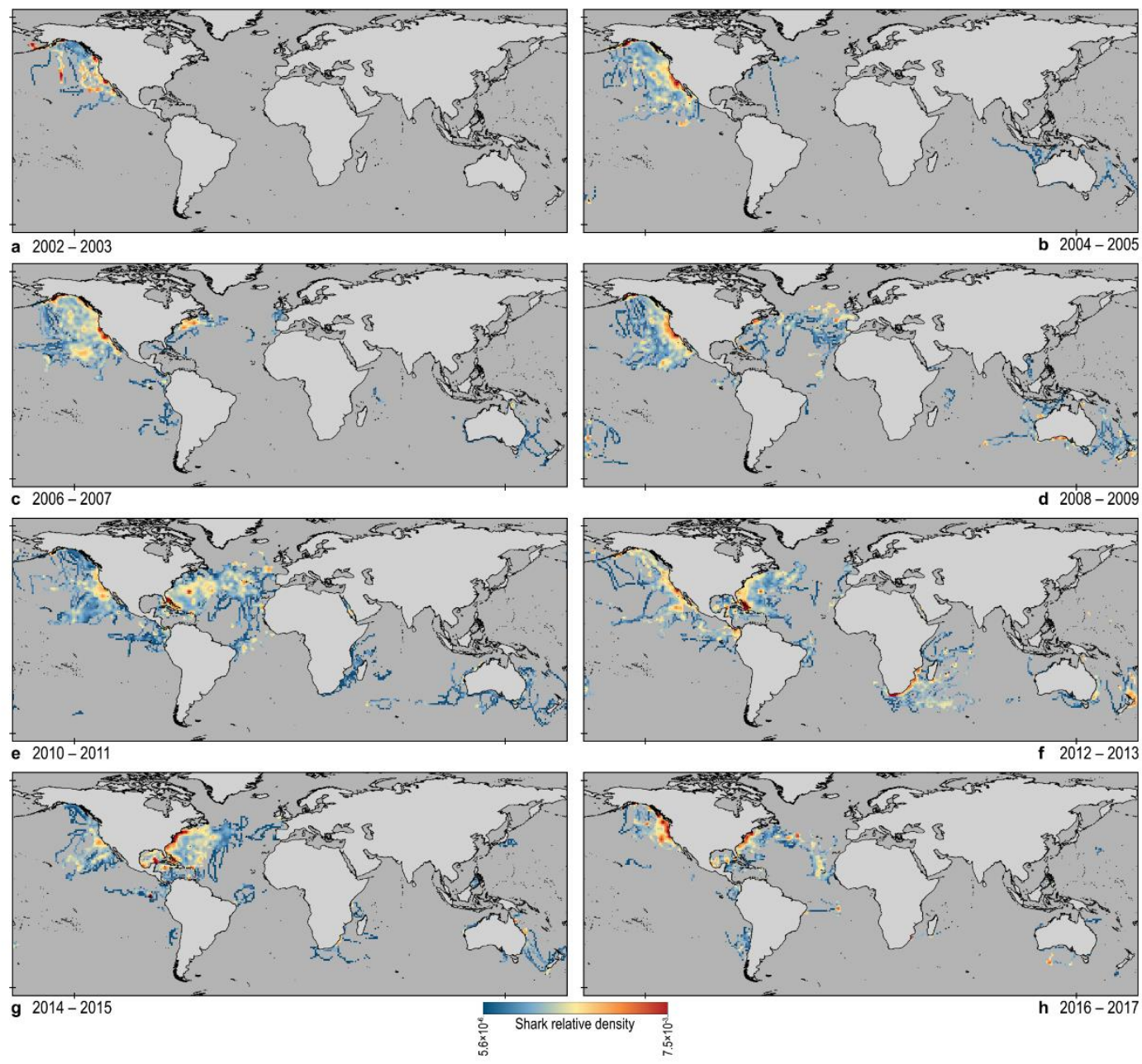

\section{Extended Data Figure 8. Between years' patterns in global spatial density of pelagic}

sharks. Mean monthly spatial density was calculated for each two year period across species.

We used consecutive two-year groups to reduce gaps in coverage. Note that there were broadscale shark tracks in the east Pacific in all eight 2-year periods (2002-03 to 2016-17), in the North Atlantic between 2006-07 and 2016-17, in the southwest Indian Ocean in 2010-11 to 2014-15, and in Oceania between 2004-05 and 2014-15. This indicates temporal consistency of shark tracks was present within the ocean regions studied suggesting spatial hotspots identified were more likely to be persistent between years. 


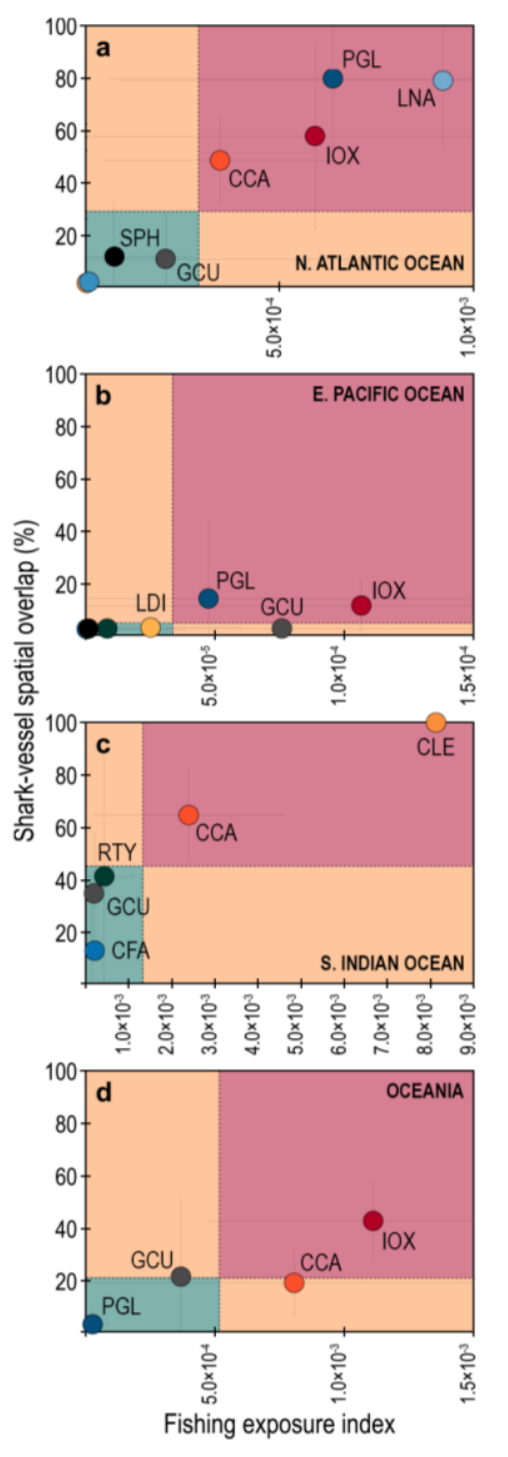

Extended Data Figure 9. Risk exposure patterns of sharks from longline fisheries between

2012-2016. (a) North Atlantic, (b) east Pacific, (c) southwest Indian oceans and (d) Oceania. Note that species patterns of exposure to risk in highest (red) and lowest risk zones (green) in the years 2012-2016, that matched shark density data with AIS longline fishing effort data directly, were very similar to patterns found for shark density (2002-17) and AIS longline fishing effort (species mean FEI) (2012-16) (shown in Fig. 3), indicating no important effect of temporal mismatched datasets on the results. 


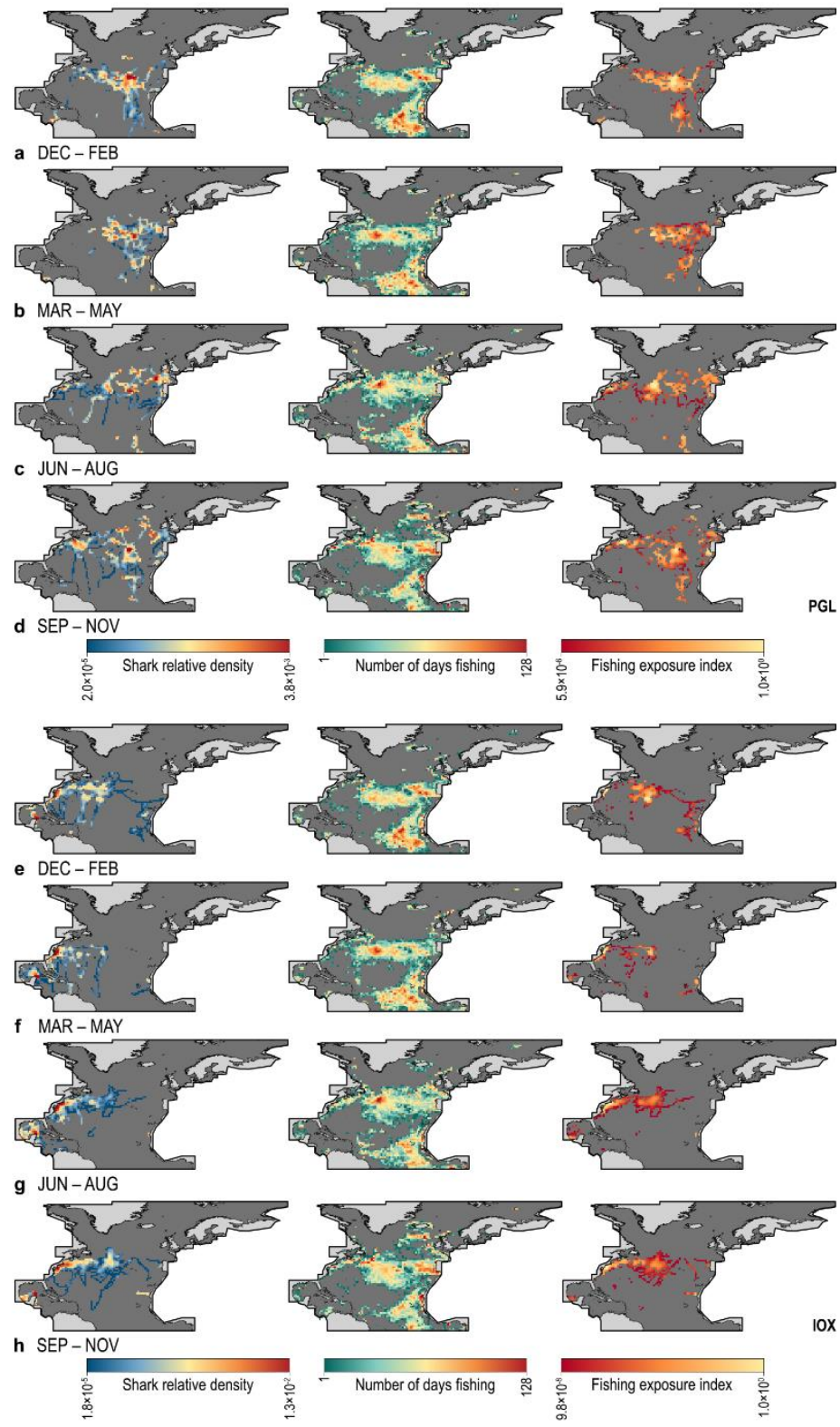

Extended Data Fig. 10. Seasonal shifts in sharks, longline vessels and overlap-fishing effort patterns. Mean quarterly relative spatial density of sharks (left map in each subpanel), longline fishing effort (days) (middle map), and mean fishing exposure index per grid cell (fishing effort sharks were exposed to in overlapped areas) (right map) for North Atlantic blue sharks (PGL) in (a) December - February, (b) March - May, (c) June - August and (d) 
Nature 572, 461-466 (2019) doi: 10.1038/s41586-019-1444-4 (Accepted version)

September to November, and for shortfin mako sharks (IOX) in (e) December - February, (f) March - May, (g) June - August and (h) September to November. 


\section{Methods}

Study animals and tagging. From 2002-2017 we tagged 1,804 pelagic sharks with satellite transmitters at multiple tagging sites in the Atlantic, Indian and Pacific oceans (Extended Data Fig. 1), including 649 in the North Atlantic, 588 in the eastern Pacific, 151 in Oceania and 153 in the southwest Indian Ocean, with 60\% of deployments occurring between 2010 and 2017 (Methods; Extended Data Fig. 1, Supplementary Tables 3-5). The number of tagged individuals varied among species and ranged from one to 280. Two satellite-transmitter tag types (position-only ARGOS, Advanced Research and Global Observation Satellite transmitter; and PSAT, Pop-off Satellite Archival Transmitter) were used. Sharks were captured with baited hooks (longlines, rod-and-line angling, or with handlines), in purse seine during commercial fishing operations, or tagged free-swimming in the water. Tags were attached to the first dorsal fin or in the dorsal musculature. All animal handling procedures were approved by institutional ethical review committees and completed by trained personnel (see Supplementary Information for details). Data were provided by the data owners to the senior author and quality checked prior to archiving in a database. Poor quality data were reported for 123 tags (72 ARGOS and 51 PSAT) due to, for example, early tag failure, premature tag pop-off, or a high percentage of locations estimated with high spatial error, e.g. raw computed geolocations over land, all of which resulted in poor state-space model fits leading to short or unreliable track reconstructions. Hence, analyses were restricted to the remaining 1,681 tracks from 1,066 ARGOS and 615 PSAT tags on sharks from 23 species ranging in total duration per species from 20 to 57,037 days with a median of 4.1 years total track time per species (Supplementary Table 3). The number of sharks tracked within each region is given in Supplementary Table 14.

Track processing. Movements of PSAT-tagged sharks were estimated using either satellite relayed data from each tag or from archival data after the tags were physically recovered. Data 
were provided as: (i) raw shark positions that were previously reconstructed using software provided by the tag manufacturers (e.g. Wildlife Computers, Redmond, USA; Microwave Telemetry, USA), where daily maximal rate-of-change in light intensity was used to estimate local time of midnight or midday for longitude calculations, and day-length estimation for determining latitude ${ }^{31,32}$; or (ii) filtered positions where a state-space model (SSM) (unscented Kalman filter with sea surface temperature, UKFSST) ${ }^{33}$ had been applied to correct the raw geolocation estimates and obtain the most probable track. In the first case, raw positions were corrected using the UKFSST SSM (UKFSST R package) in addition to a bathymetric correction applied to the initial Kalman position estimates (analyzepsat $\mathrm{R}$ add-on). A daily time-series of locations was estimated using a continuous-time correlated random walk (CTCRW) Kalman filter $^{34}$ ( $c r a w l$ R package). UKFSST geolocations were parameterised with standard deviation (S.D.) constants which produces the smallest mean deviation from concurrent ARGOS positions $^{35}$. In the latter case, the CTCRW SSM was applied to produce regular time-series.

For ARGOS transmitter tags, data were provided as raw ARGOS (Doppler frequency shift) position estimates. Location class (LC) $\mathrm{Z}$ data - assigned for a failed attempt at obtaining a position - were discarded from the dataset. The remaining raw position estimates (LC 3, 2, 1, 0, A and B) were analysed point-to-point with a $3 \mathrm{~m} \mathrm{~s}^{-1}$ speed filter to remove outlier locations. Subsequently, the CTCRW SSM was applied to each individual track, producing a single position estimate per day using model parameters implemented in the $c r a w l$ R package ${ }^{34}$.

Shark tracking data from the Tagging of Pacific Predators (TOPP) program were downloaded from the Animal Tracking Network (ATN) hosted by the Integrated Ocean Observing System (<https://bit.ly/2G7BlHn>; downloaded September 2017). Both ARGOS and light-based geolocation data in ATN had already been filtered with a Bayesian based SSM ${ }^{36}$. Briefly, the SSM was fitted to each track individually, using the WinBUGS software that conducts Bayesian statistical analyses using Markov chain Monte Carlo (MCMC) sampling ${ }^{37}$. For each 
Nature 572, 461-466 (2019) doi: 10.1038/s41586-019-1444-4 (Accepted version)

track, two MCMC chains each of length 10,000 were run and a sample of 2,000 from the joint posterior probability distribution was obtained by discarding the first 5,000 iterations and retaining every $5^{\text {th }}$ of the remaining iterations. SSM fits were posteriorly inspected for obvious problems (e.g. unrealistic movements ${ }^{11}$ ). Because two different SSMs were applied to data used in this study, we tested for possible biases in the spatial density analysis (see below) by comparing $1 \times 1^{\circ}$ density grid maps obtained with both UKFSST and Bayesian-based filtered tracks using a subset of 83 ARGOS-linked tracks in the North Atlantic (blue shark, $n=27$; mako, $n=42$; white, $n=3$; oceanic whitetip, $n=11$ ). Differences in spatial grid density between the two methods were negligible (Supplementary Fig. 1). Thus, tracks with daily locations were reconstructed for 1,681 individuals totalling 281,724 tracking days (Supplementary Table 3).

Spatial density analysis. To obtain unbiased estimates of shark spatial density, gaps between consecutive dates in the raw tracking data were interpolated to one position per day. Long temporal gaps without tag-reported location data in a reconstructed track can result in extensive interpolated movements driven by the underlying random walk model rather than a shark's movement pattern ${ }^{11}$. Although the frequency of long temporal gaps without data ( $>20$ days) in our dataset was low (Supplementary Table 15), nonetheless, any tracks with gaps without data exceeding $20 \mathrm{~d}$ were split into segments prior to interpolation, thus avoiding the inclusion of unrepresentative interpolated location estimates ${ }^{5}$. Similarly, location estimates derived for periods without data exceeding $20 \mathrm{~d}$ were also discarded from TOPP data ${ }^{11}$.

To account for biases in spatial location density associated with (i) variable track lengths and (ii) shorter tracks near the tagging location, we broadly followed the basic time weighting procedure of Block et al. ${ }^{11}$. In this study, each daily location estimate of an individual was weighted by the inverse of the number of all individuals with location estimates for the same relative day of their track: 
Nature 572, 461-466 (2019) doi: 10.1038/s41586-019-1444-4 (Accepted version)

$$
w_{i t}=1 / n_{t} \quad \text { for } \quad i \in I
$$

where $w_{\text {it }}$ is the weight for the $t^{\text {th }}$ location estimate of the $i^{\text {th }}$ individual's track, $n_{\mathrm{t}}$ is the number of total individuals with a $t^{\text {th }}$ location estimate, and $I$ is the set of individuals of all species. We calculated weights for all individuals irrespective of species to estimate the global relative spatial density of pelagic sharks (i.e. Fig. 2a; see below). Periods with gaps without data $>20 \mathrm{~d}$ were not included when weighting the locations. To minimize bias in estimates of spatial density patterns when sample sizes were lower, the modified weighting procedure of Block et $a l .{ }^{11}$ was implemented such that location weights after a threshold day of the relative track were fixed equal to the weight on the day corresponding to the $85^{\text {th }}$ percentile of track lengths. Under this weighting scheme, individual location estimates closer to the tagging location tended to receive a lower weight than later locations as, due to tag failure, transmission of satellite locations are more likely earlier in the track of an individual shark. Therefore, longer tracks received a higher total weight than shorter tracks because of the lower number of long tracks and consequently the lower value of $n_{\mathrm{t}}$ towards the end of the track. Hence, calculated spatial densities were more representative of the actual distributions and less affected by tag loss, failure or a spatial bias towards deployment location.

The weights for all individuals (equation 1) were normalised so that they summed to unity. Therefore, within the study area, all individuals contributed equally to the described global spatial density patterns:

$$
D_{i t}=\sum_{i \in I} \sum_{t=1}^{T_{i}} w_{i t}
$$

where $D_{\mathrm{it}}$ is the relative density contribution of the $t^{\text {th }}$ location estimate for individual $i$, and $T_{\mathrm{i}}$ is the number of location estimates for individual $i$. The relative density contributions for all location estimates for all individuals $\left(D_{\mathrm{it}}\right)$ were then summed within each grid cell of the study area for each month of a relative year, which gave 12 spatial relative density maps to compare 
with monthly longline fishing effort. The mean annual $D_{\text {it }}$ per grid cell for a relative year was calculated from the 12 monthly relative densities per grid cell to provide the global relative density of tracked sharks mapped in Fig. 2a. Hammerhead (3 species) and mako (2 species) shark species were analysed as taxa groups: Sphyrna spp. and Isurus spp., respectively. The spatial coverage of $1 \times 1^{\circ}$ grid cells occupied by sharks per ocean region was between $53 \%$ (East Pacific) and 25\% (Oceania) of total grid cells (Supplementary Table 5). Spatial relative densities of locations were also calculated for each of the ten most data-rich species separately at a $1 \times 1^{\circ}$ grid cell size (Extended Data Figs. 6, 7). We followed the same procedure as that given above but instead weighted by the inverse of the number of total individuals of a single species on the same relative day of their track, and with the weights for each species normalised to one.

To examine how the broad spatial distribution of sharks between years may have changed we re-calculated the relative density contributions for all location estimates for all individuals $\left(D_{\text {it }}\right)$ together within each of eight consecutive two-year classes starting in 2002 (Extended Data Fig. 8). Each daily location within a class was weighted by the inverse of the number of individuals with location estimates for the same relative day of the 2 years (e.g. $1^{\text {st }}$ January 2012 is the relative day number 1 of all tracks in each of two years that were active on that date). Similar to the weighting scheme applied to the main data, periods with gaps without data $>20 \mathrm{~d}$ were not included when weighting the locations. After the $85^{\text {th }}$ percentile of the track length, daily weights were fixed as before. Total weights for all individuals within each two-year class were normalised to one. In addition, due to a mismatch in the years of data availability between sharks and fishing vessels, exposure risk (overlap and fishing exposure index, FEI) was recalculated for the period between 2012 and 2016 that was common to both sharks and longline fishing vessels (Extended Data Fig. 9). Relative density of all individuals $\left(D_{\text {it }}\right)$ was re- 
calculated based on the weighting scheme described above, considering only individuals whose tracks were within the $2012-2016$ period.

Fishing vessel geolocation data. The Automatic Identification System (AIS) was developed as a vessel safety and anti-collision system with global coverage, rather than to track fishing vessels for fishery management purposes ${ }^{19-22}$. However, its global coverage of locations of many thousands of ships through time enables fishing effort distribution to be analysed ${ }^{19-22}$. Here, fishing effort (hours of fishing) data gridded at $0.01^{\circ}$ by flag state and estimated gear type were obtained from Global Fishing Watch (GFW) (available at <https://bit.ly/2GmF7Me>). GFW used raw AIS vessel tracking data obtained from ORBCOMM via their AIS-enabled satellite constellation (<https://bit.ly/2TuAdkb $>$ ) to calculate fishing effort and derive the gridded data, described in detail in Kroodsma et al. ${ }^{19}$. Briefly, GFW uses two neural network algorithms to categorize different types of fishing gear, e.g. drifting longlines, purse seines, in addition to estimating the spatio-temporally resolved locations where fishing gears were most likely deployed by individual vessels ${ }^{19}$. We used the GFW gridded fishing effort data in the years 2012 to 2016 for all gear types, and for estimated drifting pelagic longlines and purse seines. The GFW gear-type classification algorithms are being continuously refined to correct for acknowledged contamination of some gear types with others in some regions ${ }^{19}$, e.g. drifting longlines with bottom-set longlines off New Zealand. For each type in this study, we summed the number of hours fishing in a month (expressed as days, where $24 \mathrm{~h}$ of fishing effort $=1$ day) within each $1 \times 1^{\circ}$ grid cell to provide 12 monthly global fishing effort maps. The mean annual fishing effort per grid cell in a relative year was calculated from the 12 monthly fishing effort maps. Global distributions of fishing effort for all gear types, longlines and purse seines were mapped separately and overlaid by shark spatial relative density of locations for all individuals $\left(D_{\mathrm{it}}\right)$ to determine spatial overlap intensity (fishing effort sharks were exposed to; see FEI below). AIS data coverage increased from 2012 
to 2016 as more satellite AIS receivers were launched and commenced operation ${ }^{19}$. However, the global spatial distribution of longline vessel fishing effort was broadly similar across years (Supplementary Fig. 2) and variation in annual maximum fishing effort displayed no increasing trend over time, indicating our calculated mean annual fishing effort for 2012-2016 did not overestimate spatial overlap or fishing effort but can be considered conservative (Supplementary Fig. 2). To test that the numbers of AIS longline fishing days per grid cell were representative of actual fishing effort as measured by the numbers of baited hooks deployed by longline vessels, we correlated Atlantic AIS fishing days with ICCAT observed hook data (downloaded from https://bit.ly/2GmrYTt). We compared the total number of observed hooks in ICCAT data at a $5 \times 5^{\circ}$ grid cell size (the finest spatial resolution for these ICCAT data) with the total number of fishing days in the AIS dataset, also at $5 \times 5^{\circ}$. To calculate the AIS fishing effort days in each $5 \times 5^{\circ}$ grid cell we summed the days in the $1 \times 1^{\circ}$ cells that fell within each $5 \times 5^{\circ}$ cell. Data were used from 2015, the most recent year for which we had both ICCAT hook data and comprehensive AIS longline coverage.

Shark and fishing effort environment modelling. To model shark and fishing vessel distributions in relation to environmental variables, data were extracted from online databases (Supplementary Fig. 3). The environmental variables were selected based upon their demonstrated importance in affecting shark occurrence and included: (i) sea water temperature $\left({ }^{\circ} \mathrm{C}\right)$ (abbreviation used in models: sea surface temperature, SST; temperature at $100 \mathrm{~m}$, TEM_100) known to influence the presence of many pelagic shark species ${ }^{5,11}$; (ii) maximum thermal gradient $\left(\Delta^{\circ} \mathrm{C} / 100 \mathrm{~km}\right)(\mathrm{TGR})$ influences shark spatial density ${ }^{5}$, and was calculated here based on the SST data and using maximum gradient maps by determining where for each pixel a geodetic-distance-corrected maximum thermal gradient was identified; (iii) sea water salinity (psu) (SAL), an important determinant of habitat use in some sharks ${ }^{1,38}$; (iv) sea surface height above geoid (m) ( $\mathrm{SSH})$ that influences shark presence ${ }^{5}$ and catches by fisheries ${ }^{6} ;(\mathrm{v})$ 
ocean mixed layer depth thickness or thermocline depth (m) (MLD) that affects pelagic shark foraging behaviour ${ }^{39}$; (vi) mass concentration chlorophyll $a$ in sea water $\left(\mathrm{mg} \mathrm{m}^{-3}\right)$ (CHL) as a proxy for productivity that often characterises preferred habitats of sharks ${ }^{5,39}$; (vii) mole concentration of phytoplankton expressed as carbon in sea water concentration $\left(\mathrm{mmol} \mathrm{m} \mathrm{m}^{-3}\right)$ (PHY) as a direct measure of productivity; (viii) net primary production of biomass expressed as carbon per unit volume in sea water per day $\left(\mathrm{g} \mathrm{m}^{-3} \mathrm{~d}^{-1}\right)$ (NPP) quantifying productivity; and (ix) mole concentration of dissolved molecular oxygen in sea water $\left(\mathrm{mmol} \mathrm{m}{ }^{-3}\right)$ (DO) that can strongly influence shark space use ${ }^{1}$. Environmental datasets $i$ to $v$ were downloaded from Copernicus Marine Environment Monitoring Service (CMEMS) Global Ocean Physics Reanalysis product (https://bit.ly/2MOJeSy; downloaded November 2017) and datasets $v i$ to $i x$ from CMEMS Global Ocean Biochemistry Hindcast product (https://bit.ly/2TwNbOq; downloaded November 2017). CMEMS data were available for 2002 to 2014 from the surface to $5,500 \mathrm{~m}$ as monthly datasets. Overall averages (2002-2014) were calculated at a $1 \times 1^{\circ}$ grid cell resolution for surface and $100 \mathrm{~m}$ depth layers (with the exception of SSH and MLD; Supplementary Fig. 3). Most of these variables and interactions are also considered important for explaining fishing patterns ${ }^{5,6}$.

We developed and compared a set of generalised additive models (GAMs) with a gaussian family and an identity link using the log-transformed relative density of locations of all individual sharks $\left(D_{i t}\right)$ as response variable. We used the relative density of sharks rather than presence/absence data because our main aim was to highlight the areas where highest overlap with fishing effort might occur. Because we were interested in identifying areas (grid cells) with the highest overlap, and understanding how general environmental variables might influence shark density in specific locations, we considered the relative density for all 23 shark species combined without considering random effects per species. All environmental variables were standardised (mean-centred and divided by the standard deviation) and colinearity 
checked prior to inclusion in the models. Highly skewed environmental variables were logged before standardisation, this included most predictors at the surface (except for SAL and SSH) and also NPP (for sharks only) and TGR at 100 m (TGR_100). All possible combinations of 16 variables were not undertaken due to colinearity. Rather, we focused on testing ecologically relevant hypotheses. A description of the general hypothesis tested with each model included in the model set is given in Supplementary Table 7. Including models with a reduced number of variables was necessary as some variables were colinear and those variables were included in other models. Because sharks respond to surface and subsurface thermal gradients which often support higher biological productivity ${ }^{5,6,11,39}$, we tested for interactions between MLD and SST, CHL and MLD at $100 \mathrm{~m}$ (MLD_100), CHL at $100 \mathrm{~m}$ (CHL_100) and TEM at $100 \mathrm{~m}$ (TEM_100), MLD and TGR at the surface, MLD and CHL_100,CHL_100 and TEM_100, and between SAL and TEM_100.

GAM with a Tweedie distribution and log link function provided the best modelling approach for the fishing effort data (including zeros in grid cells), as this distribution includes a family of probability distributions including normal, gamma, Poisson and compound Poisson-gamma. We considered two response variables separately: fishing effort (days of fishing per grid cell) of all AIS fishing vessels, and fishing effort of AIS longline vessels only. We did not consider presence/absence data since our aim was to understand how environment influenced variations in fishing effort. In our model set we included different combinations of a total of the same 16 explanatory environmental variables used for shark density modelling (see previous section; Supplementary Table 7), and also a null (all terms equal to zero), intercept-only model. The dimension basis for all terms was limited to 5 (i.e., $k=5$ ) to assist controlling for overfitting ${ }^{40}$. We then used the Akaike's information criterion (AIC) ${ }^{41}$ to compare the models in the model set for all sharks and fishing vessels. We assessed the relative strength of evidence for each model using the weights of AIC, and the goodness of fit of each model by calculating the 
Nature 572, 461-466 (2019) doi: 10.1038/s41586-019-1444-4 (Accepted version)

percentage of deviance explained (\%DE). All models were implemented in $\mathrm{R}$ using the $m g c v$ package $^{42}$.

Shark/vessel spatial overlap and effort. The spatial overlap (\%) between an individual tracked shark and fishing effort was calculated as the number of grid cells that sharks and fishing effort (days) occurred in the same $1 \times 1^{\circ}$ grid cells in an average month, as a function of all shark grid cells occupied and standardised for shark track length, and summarised as:

Spatial overlap $(\%)=100\left(n_{\mathrm{o}} / n_{\mathrm{c}}\right)$

where $n_{\mathrm{o}}$ is the number of grid cells occupied by an individual tracked shark that overlap with grid cells with fishing effort, and $n_{\mathrm{c}}$ is the total number of grid cells occupied by an individual tracked shark. The mean monthly spatial overlap of an individual shark was determined from monthly spatial overlap values, and the mean monthly spatial overlap per species was calculated by averaging the mean monthly individual spatial overlap values across all individuals of a species within each ocean region. A fixed $1 \times 1^{\circ}$ geographic grid cell (where $1^{\circ}=110.6 \mathrm{~km}$ ) was chosen as it was the approximate length of high seas longlines, i.e. $100 \mathrm{~km}$ long with an average of 1,200 baited hooks $^{5}$ that attract fish over long distances ${ }^{19}$, it was similar to the broad light-based geolocation error field of PSAT tags ( $n=615$ sharks; $37 \%$ of the total tracks) after SSM processing that we used here, generally shown to be $\sim 0.4-1.5^{\circ}$ latitude $(\sim 45$ - $167 \mathrm{~km}$; refs. 31, 43-45), and it exceeded the upper 95\% confidence intervals of the mean daily movement distances of the widest ranging sharks tracked (Supplementary Table 16). In addition, the $1 \times 1^{\circ}$ grid cell size was suitable to reduce the effects of gaps in AIS coverage that at smaller grid sizes could potentially result in significant unrecorded fishing effort per grid cell ${ }^{19-22}$. To examine the effect of grid cell size on spatial overlap estimates ${ }^{19,46}$ we calculated the overlap of all sharks tracked with ARGOS transmitters, where locations estimated from SSMs were fitted to ARGOS observations (e.g. $2.4-5.5 \mathrm{~km}$ spatial accuracy ${ }^{47}$ ), 
Nature 572, 461-466 (2019) doi: 10.1038/s41586-019-1444-4 (Accepted version)

with longline fishing effort at $2 \times 2^{\circ}, 1 \times 1^{\circ}, 0.75 \times 0.75^{\circ}, 0.50 \times 0.50^{\circ}, 0.25 \times 0.25^{\circ}$ and 0.10 $\times 0.10^{\circ}$ grid cell sizes (Extended Data Fig. 4; Supplementary Fig. 4).

An estimate of an individual shark's exposure to fishing effort within each grid cell occupied during its observed track was termed fishing exposure index (FEI) and calculated as:

$$
F E I=\frac{\sum_{i=1}^{n} f_{i} d_{i}}{n}
$$

Here FEI pertains to an individual shark per month in a given year. The term $f_{\mathrm{i}}$ is the fishing effort (vessel days) in grid cell $i$ occupied by a shark during its track; $d_{\mathrm{i}}$ is the relative density contribution for all location estimates for an individual shark summed in grid cell $i$ of its track (i.e. location estimates of an individual were weighted by the inverse of the number of total individuals of a single species on the same relative day of their track, and with the weights for each species normalised to one; see Spatial Density Analysis); and $n$ is the number of grid cells occupied by an individual shark during its track in a given month of a given year. Individual mean FEI was calculated for an individual shark by averaging an individual shark's monthly FEI values through time (over the duration of its observed track in monthly steps). To estimate the typical exposure within a species, individual species mean FEI was calculated by averaging individual shark mean FEI values for that species within each ocean region (Figs. 3, 4).

To map the mean monthly spatial variation in overlap and fishing effort (fishing exposure) within the space used by sharks (Fig. 2c), we calculated the product of $D_{\text {it }}$ and $f_{\mathrm{i}}$ in each grid cell in each month of a relative year across individual sharks (regardless of species), and averaged across the 12 months within each grid cell. In addition, for comparing temporally matched shark-vessel spatial overlap and fishing effort in 2012 - 2016, we repeated the calculation above but including only those individuals (species) present within these years by multiplication of $f_{\mathrm{i}}$ with the re-calculated $D_{\text {it }}$ for those years only (see Spatial Density Analysis for details). 
To test for differences in exposure risk of sharks to fishing activity between different species within the general fishing areas designated by the Food and Agriculture Organization of the United Nations (FAO) (Extended Data Fig. 1c), we undertook statistical analysis of exposure risk calculated for each shark as the product of the mean monthly spatial overlap and mean monthly fishing effort. Since data were not normal (Shapiro-Wilk normality test, $p<0.05$ ), a Kruskal-Wallis (KW) test was performed (with pairwise Wilcoxon rank sum tests as a posthoc test). Because of differences in the number of tagged individuals per species, groups of $>25$ sharks per species were randomly selected and the KW test performed. This procedure was repeated 1,000 times and the percentage of times that significant differences were observed were recorded. Species with fewer than 25 individuals tracked were removed from the analysis. Given the lower numbers of sharks tracked in the southwest Indian Ocean and Oceania regions (Supplementary Table 14), statistical tests were restricted to the North Atlantic and eastern Pacific regions. In the Atlantic selected species were: P. glauca $(n=152)$, Isurus spp. $(n=$ 120), G. cuvier $(n=131), C$. carcharias $(n=26)$, C. longimanus $(n=99)$, L. nasus $(n=46)$, C. leucas $(n=38)$ and Sphyrna spp. $(n=40)$; Pacific, species were: P. glauca $(n=112), I$. oxyrinchus $(n=113)$, L. ditropis $(n=172), R$. typus $(n=77)$ and $C$. carcharias $(n=59)$.

Shark landings. Mean annual pelagic shark landings (t) by species/taxa groups were obtained from the FAO database (<FAO.org/fishery/statistics/global-capture-production/query/en>; downloaded September 2018) and related to the median monthly FEI of each species/taxa group. Landings reported for the North Atlantic (northwest, northeast, western central and eastern central Atlantic) between 2007 and 2016 were used in the analysis since it spanned the main period that most sharks were tracked (70\% between 2007-2017) and longline fishing effort was monitored (2012-2016). Data were extracted for eight species or taxa groups that are regularly caught by shelf and/or high-seas fisheries in the North Atlantic, the region in which most tags were deployed. The species/taxa groups were: P. glauca, I. oxyrinchus, $C$. 
Nature 572, 461-466 (2019) doi: 10.1038/s41586-019-1444-4 (Accepted version)

longimanus, C. leucas, L. nasus, G. cuvier, C. carcharias, and hammerheads (Sphyrna spp.) comprising S. lewini, S. mokarran and S. zygaena.

Reporting summary. Further information on fieldwork, source code and data analyses are available in the Nature Research Reporting Summary linked to this paper.

Data availability. The source code used to undertake analyses and to prepare figures, in addition to the derived data underlying Fig. 2 maps (shark relative spatial density; longline fishing effort; and shark- longline overlap and FEI) and Fig. 3 plots (spatial overlap and FEI) are freely available on GitHub (github.com/GlobalSharkMovement/GlobalSpatialRisk).

\section{Additional references}

31. Wilson, R.P., Ducamp, J.-J., Rees, W.G., Culik, B.M., Niekamp, K. Estimation of location: global coverage using light intensity. In Wildlife Telemetry (eds Priede, I.G., Swift, S.M.), p. 131-134 (Ellis Horwood, Chichester, UK, 1992).

32. Delong, R.L., Stewart, B.S., Hill, R.D. Documenting migrations of northern elephant seals using day length. Mar. Mamm. Sci. 8, 155-159 (1992).

33. Lam, C., Nielsen, A., Sibert, J. Improving light and temperature based geolocation by unscented Kalman filtering. Fish. Res. 91, 15-25 (2008).

34. Johnson, D.S., London, J.M., Lea, M.-A. \& Durban, J.W. Continuous-time correlated random walk model for animal telemetry data. Ecology 89, 1208-1215 (2008).

35. Sippel, T., Holdsworth, J., Dennis, T., Montgomery, J. Investigating behaviour and population dynamics of striped marlin (Kajikia audax) from the southwest Pacific Ocean with satellite tags. PLoS One 6, e21087 (2011).

36. Jonsen, I.D., Flemming, J.M., Myers, A.E. Robust state-space modeling of animal movement data. Ecology 86, 2874-2880 (2005). 
Nature 572, 461-466 (2019) doi: 10.1038/s41586-019-1444-4 (Accepted version)

37. Lunn, D. J., Thomas, A., Best, N., Spiegelhalter, D. WinBUGS - a Bayesian modelling framework: 472 concepts, structure, and extensibility. Statistics Comput. 10, 325-337 (2000).

38. Ward-Paige, C.A., Britten, G.L., Bethea, D.M., Carlson, J.K. Characterizing and predicting essential habitat features for juvenile coastal sharks. Marine Ecology 36, 1-13 (2014).

39. Queiroz, N., Vila-Pouca, C., Couto, A., Southall, E.J., Mucientes, G., Humphries, N.E., Sims, D.W. Convergent foraging tactics of marine predators with different feeding strategies across heterogeneous ocean environments. Front. Mar. Sci. 4, 239 (2017).

40. Fisher, R., Wilson, S.K., Sin, T.M., Lee, A.C. \& Langlois, T.J. A simple function for fullsubsets multiple regression in ecology with R. Ecol. Evol. 8, 6104-6113 (2018).

41. Burnham, K. P., Anderson, D.R. Multimodel inference: understanding AIC and BIC in model selection. Sociological Meth. Res. 33, 261-304 (2004).

42. Wood, S.N. Fast stable restricted maximum likelihood and marginal likelihood estimation of semiparametric generalized linear models. J. Roy. Statistical Soc. B 73, 3-36 (2011).

43. Teo, S.L.H., Boustany, A., Blackwell, S., Walli, A., Weng, K.C. \& Block, B.A. Validation of geolocation estimates based on light level and sea surface temperature from electronic tags. Mar. Ecol. Prog. Ser. 283, 81-98 (2004).

44. Nielsen, A., Bigelow, K.A., Musyl, M.K. \& Sibert, J.R. Improving light-based geolocation by including sea surface temperature. Fish. Oceanogr. 15, 314-325 (2006).

45. Sims, D.W. Tracking and analysis techniques for free-ranging shark movements and behaviour. In Sharks and Their Relatives II - Biodiversity, Adaptive Physiology and 
Nature 572, 461-466 (2019) doi: 10.1038/s41586-019-1444-4 (Accepted version)

Conservation (Carrier, J.C., Musick, J.A., Heithaus, M.R., eds), p. 351 - 392 (Boca Raton, FL, USA: CRC Press, 2010).

46. Amoroso, R.O., Parma, A.M., Pitcher, C.R., McConnaughey, Jennings, S. Comment on “Tracking the global footprint of fisheries". Science 361, eaat6713 (2018).

47. Lowther, A.D., Lydersen, C., Fedak, M.A., Lovell, P., Kovacs, K.M. The Argos-CLS Kalman filter: Error structures and state-space modelling relative to Fastloc GPS data. PLoS One 10, e0124754 (2015). 